\title{
FUBImethod: Strategies to engage Children in the Co-Design of Full-Body Interactive Experiences
}

\author{
Marie-Monique Schaper, Ole Sejer Iversen*, Laura Malinverni, Narcis Pares \\ Universitat Pompeu Fabra, c. Roc Boronat 138, 08018 Barcelona, Spain \\ \{mariemonique.schaper, laura.malinverni, narcis.pares\}@upf.edu \\ Tel.: (+34) 935422631 \\ * Aarhus University, Helsingforsgade 14, 8200 Aarhus, Denmark \\ oiversen@cavi.au.dk, Tel.: (+45) 87161996
}

Corresponding author: Marie-Monique Schaper; mariemonique.schaper@upf.edu

\begin{abstract}
In this paper, we present the FUBImethod, a method based on six stages to co-design interactive experiences based on Full-Body Interaction. The FUBImethod aims specifically to engage children in co-design processes and to benefit from their natural playfulness and expertise in movement. This approach allows designers to go beyond the surface level of content-driven ideas by raising awareness of the body and space, and by proposing techniques that help the design team to understand and incorporate the specific qualities that constitute Full-Body Interaction. We also propose strategies to strengthen the children's perspective in the design process in reaching a common agreement in the design goals and the selection of adequate design choices within the design team. We ground our theoretical discussions on the outcomes of the research project "Evaluation-Driven Design", the goal of which was the exploration and definition of adequate research and design methods in FullBody Interaction.
\end{abstract}

Keywords: Design Methods; Co-Design; Embodiment; Full-Body Interaction; Children

\section{Introduction}

The concept of Full-Body Interaction describes how the relation of the user's body moving in space with the computer-controlled system supports meaning-making in the experience. During the last decade, there has been a growing tendency in the development of learning environments based on Full-Body Interaction in the Child-Computer Interaction community (Malinverni and Pares, 2014a). Previous research points towards the benefits of Full-Body Interaction to foster learning (Revelle 2013). These benefits are based on the opportunities that Full-Body Interaction may offer to involve the users at different levels (e.g. sensorimotor, cognitive and affective) and to facilitate the construction of knowledge through actions and sensorimotor experiences (Malinverni et al., 2016c). This potential is particularly relevant for experiences for children because they learn naturally by engaging and exploring the world through their bodies.

More specifically, Full-Body Interaction provides us with a medium to capture how humans navigate, discover and understand the world. This concept does not suggest that designers 
need to make simulations of the physical world. Rather, for the design of the interactive experience, it implies to take advantage of the natural ways in which children deploy themselves in the physical world and make sense of it. In this regard, Full-Body Interaction entails a way to support the natural process through which they develop themselves as human beings. One aspect is how children learn new concepts, ideas, activities, and skills, as has been described by many authors from constructivism to constructionism (Papert, 1980; Piaget, 1955; Resnick, 2002), from free exploration to the analysis of specific properties (Zuckerman and Resnick, 2005). In all these developmental processes, the embodied nature of children's exploration and discovery are an essential part of the learning experience. In addition, research has shown how children create their own personal conception of the world and of themselves both physically and conceptually (Ackermann, 2004). In other words, our cognition is developed through our experience of the world (Barsalou, 2008; Gibson, 2014; Niedenthal, P. M.; Barsalou, L. W.; Winkielman, P.; KrauthGruber, S.; Ric, 2005; Varela, 1996) by perceiving it and constantly acting within it through our bodies.

A second aspect of how Full-Body Interaction may support learning is how children make connections between the space and other properties surrounding them in an interactive experience that are often not available in other types of Human-Computer Interaction $(\mathrm{HCl})$. One clear example is our sense of scale in space and the actions we perform in it. The sense of scale helps us to compare our bodies and actions to objects and volumes around us (Mora-Guiard and Pares, 2014) and understand how we fit in our world at that scale. These spatial properties are reflected in our language (Lakoff and Johnson, 1999) as well as in our non-verbal communication, such as through gestures (Goldin-Meadow and Alibali, 2002), showing how our experience of the world through our bodies trickles into our understanding of it.

Finally, Full-Body Interaction may also help us capture how we relate to other people and living beings. In other words, we can be capable of mediating experiences to foster space exploration and discovery. These experiences trigger the externalization of our accomplishments and allow us to share them with peers (Vygotsky, 1980). We can then internalize these events to assume them as part of our development as human beings. But we can also use them in natural ways of undertaking socialising acts, from the most incipient ones that lead to a social initiation, to the most complex of cooperation and collaboration, in dyads or large groups, with our minds and with our bodies.

However, it is important to note each type of interaction (from desktop with keyboard and mouse, to tangible interaction with meaningful objects, Augmented Reality, or interaction with mobile devices through a simple touch screen, including Full-Body Interaction) defines a different type of medium with its specificities, advantages and disadvantages. Therefore, each one can be extremely useful or completely inadequate depending on the application, its context and the way we want to mediate the interactive experience to the users. Our research focuses on the benefits of Full-Body Interaction and on understanding when its application can be justified.

Over the last decade most interactive experiences based on Full-Body Interaction have been developed according to a Designer-Driven approach (Malinverni and Pares, 2014b); i.e., all decisions related to the design of the experience and the system were only taken by the designers. In this paper, we introduce a genuine user-driven design approach engaging 
children in the process of co-designing interactive experiences based on Full-Body Interaction. In general, scholars have stressed the fact that often, systems developed without user participation do not properly grasp users' understandings and worldviews (Muller and Druin, 2010), which are essential to frame an effective learning experience. Moreover, FullBody Interaction, as part of the embodied interaction paradigm (Dourish, 2001), involves the design of spatial, sensorimotor and aesthetic aspects of the experience. These aspects entail the challenge being aligned with the definition of the learning contents and interaction design choices. However, previous research has shown that in general, systems based on Full-Body Interaction often incorporate the notion of the body and space only on a functional level (Malinverni and Pares, 2014b). For instance, some designers tend to trivialize the concept of Full-Body Interaction and adapt mechanics from traditional WIMP (Windows, Icons, Menus, Pointer) interfaces, by using the body as a mere mouse-cursor to click on digital buttons and choose menu options such as those used in desktop applications, for example.

Responding to these shortcomings, a growing number of studies have proposed initial efforts to involve end users in the design of Full-Body Interaction Learning Environments (FUBILEs) (Enyedy et al., 2012; Grønbæk et al., 2007; Höysniemi et al., 2005; Landry et al., 2012; Malinverni et al., 2016c; Schaper and Pares, 2016). Several of these studies have involved users to better understand their previous knowledge, interests and motivations towards the learning topic (Enyedy et al., 2012; Malinverni et al., 2016c; Schaper et al., 2014). However, many of these approaches are based on research methods developed for traditional WIMP interfaces and primarily aim to co-define content-related aspects. Consequently, these approaches run the risk of excluding sensorimotor and experiential aspects. This becomes particularly critical in Full-Body Interaction since it is based on theoretical frameworks related to embodied cognition and experiential learning; i.e., it suggests that human bodies play a central role in shaping and understanding interactions in experiences of the world (Svanæs, 2013). Novel design strategies that challenge the WIMP approach can be found, for instance, in the research of somaesthetic- and dance-inspired interactions. These approaches focus on embodied characteristics of human movement in design such as movement qualities (Alaoui et al., 2015, 2012) and somatic experiences (Françoise et al., 2017; Höök, 2010).

Designing for Full-Body Interaction with young users requires designers to research, understand and include children's perspectives on the embodied experience. But involving children in the design of technology has its challenges. Previous research has pointed out that in general there is a lack of adequate design methods to allow children to fully participate in the design process (Iversen and Dindler, 2013). Iversen and Dindler (2013) claim that the research of design methods for children has often focused on the "notions of what children cannot do", such as the limits of their cognitive and motor skills. However, we argue that research on embodied interaction can specifically benefit from children's playfulness and constant movement.

Most people lose their natural playfulness in adulthood due to daily routines, obligations and the awareness of socio-cultural norms. These developmental changes lead some adults to feel uncomfortable during tasks that involve play and the performance of unusual movements (Hickey-Moody et al., 2016). Moreover, adults often have difficulties to reimagine their motivations for certain childhood experiences (Yip et al., 2017), specifically those which include body sensations. In a sense, we could, therefore, conclude that childhood is a special life period in which children seem to be more strongly connected to their bodies than adults. Consequently, these skills and knowledge make them experts not only in the design of 
embodied interaction but specifically for embodied technologies and experiences that are designed for them as users.

Building on these findings, we propose a structured Full-Body Interaction co-design method: the FUBImethod. We understand a method according the definition by Walsh et al. (2013) as a collection of techniques used in conjunction with a larger design philosophy. The main goal of the FUBImethod is to help co-designers in Full-Body Interaction to guide design teams including children and their design sessions with a number of techniques to foster embodied awareness. This procedure makes the body the focus and protagonist during the design. With this method, we particularly aim to engage children in co-design processes and to benefit from their natural playfulness and expertise in movement. Therefore, we give high priority to providing tools that make children understand how their bodies mediate their experience of the world, and hence how they can propose computer-based activities in which the body plays a meaningful role. On the other hand, we propose strategies to strengthen children's perspectives in the design process and achieve a common agreement in the design goals and design choices within the design team.

The paper is structured as follows: In chapter two, we provide an overview of related work within Child-Computer Interaction. Chapter three provides an exhaustive account of the FUBImethod emphasizing how this particular method can contribute to the design of FullBody Interaction based on the valuable input from children. We discuss how the FUBImethod contributes to existing research on Full-Body Interaction in chapter four, and conclude the paper by outlining how other research fields could benefit from children's skills and expertise.

Throughout the paper, we will be describing co-design processes and hence will be referring to a multi-faceted team of people. Namely we will be referring to interaction design experts that will be leading the design process through the FUBImethod that we describe, and to which we will refer as the "design experts". We will be also referring to experts in the field of application, such as teachers in educational applications, museum curators in heritage applications, etc., and to whom we will be referring from now on as "field experts". Finally, we will also be referring to the children who will be the target users of the final experience, but who also have a central role in the co-design process; we shall refer to them as "children". The whole team will be referred to as the "co-design team" and its members will be the "codesigners" as a whole.

\section{Related Work}

\subsection{Challenges in Full-Body Interaction Design}

Designing for Full-Body interactive experiences requires understanding the underlying theoretical framework of this concept and the ways in which it can support learning. However, research in $\mathrm{HCl}$ has often been primarily concerned with the comprehension of the user's mind, but little attention has been paid to its connection to the bodily experience (Malinverni and Pares, 2014b). This strict separation between body and mind has its roots in fundamental principles of Western culture. Descartes, in this context, formulated the theory of Cartesian mind-body dualism in which he defined the human as an immaterial mind having a physical body. According to him, a human being can be considered a self-conscious entity whose body is controlled, similarly to a machine, by natural laws (Svanæs, 2013). In contrast to this dualistic vision, in recent years, the concept of learning with and through the body has 
been gaining increasing attention in contemporary studies of embodied interaction. This research is based on theoretical frameworks related to embodied cognition. It suggests that cognition and knowledge cannot be restricted only to the mind but they arise in the relation between the mind, the body and the world (Wilson, 2002). Hence, human bodies play a central role in shaping interactions and experiences in the world and their understanding (Merleau-Ponty, 1962). In contrast to Descartes, Merleau-Ponty argues that every individual is a "lived body" in the world whose self-awareness is closely connected to the interaction with the physical environment and with others. Thus, according to Svanæs (2013) the emphasis on the lived body as a steering motor for the user experience represents a radical break with Cartesian body-mind dualism.

These theories are supported by research in the field of cognitive science, which suggests that cognitive processes are influenced by our own physical activity and imitation of others' behaviour. Particularly during the first years of life, movement (Kontra et al., 2012) and the ability to imitate (Jones, 2009) form an integral part of child development for motor, cognitive and social skills. Within this framework, we concentrate our research on the benefits of FullBody Interaction. This interaction concept takes advantage of users' motion and body capabilities to interact and construct meaning in physical and virtual space. From a theoretical perspective, Full-Body Interaction has the potential to support learning (Revelle, 2013). Research in this field is grounded on the hypothesis that involving users at different levels (e.g. sensorimotor, cognitive and affective) and the performance of specific gestures during the interactive experience may facilitate the construction of knowledge (Freiler, 2008; Glenberg, 2010; Goldin-Meadow and Alibali, 2002). At the same time, conceptual changes can be shaped by the specific physical characteristics of the environment (Hornecker and Buur, 2006; Márquez Segura et al., 2016), socio-cultural influences (Hornecker et al., 2014) and the living experience of others' actions in the world (Ackermann, 2004).

When designing learning experiences for Full-Body Interaction, the design team must tackle three fundamental challenges.

The first challenge is the need to make sure that Full-Body Interaction is an adequate type of interaction for the contents for communication. Scholars have established benefits of activities based on using embodied resources to strengthen the sensorimotor, cognitive, and socio-emotional aspects of the user experience (Antle, 2013).

The second challenge concerns the need to carefully align the design of the embodied activities with the content of the experience and children's level of comprehension (Malinverni and Pares, 2014b). Recent studies claim that, on the one hand, the design of embodied learning technologies for children often ignores the variability in their cognitive development and behaviours. On the other hand, researchers do not consider the contextual variables that influence the situated use of interactive products for them (Antle, 2013). Therefore, it is important to research aspects related to children's development, understanding and worldviews such as previous knowledge, interests, and values.

The third challenge refers to the need to develop methods that facilitate designing for and with the body. Designing for embodiment involves understanding users' sensations of bodily, spatial and social aspects of the experience. Particularly, when working with children, adult designers cannot rely on their own childhood experiences to inform technological designs (Yip et al., 2017), particularly not when we design for children's specific felt-experience 
during play. However, most co-design techniques have been developed for traditional WIMP (Windows, Icons, Menus, Pointer) interfaces and principally aim to co-define content-related aspects. Consequently, these approaches run the risk of focusing on the cognitive aspects of the experience only, and neglect the sensorimotor and experiential counterparts. Furthermore, for most designers, the notion of Full-Body Interaction is a new experience, which makes it difficult for them to imagine how FUBILEs could work. They therefore struggle to contribute new ideas to the design process.

Several researchers have questioned the methodological appropriateness of the techniques and methods employed to design for embodied learning. The risks of applying criteria that conflict with the roots of embodiment have been highlighted (Harrison et al., 2011). Antle (2013) highlights the current tendency for positivists' research methods that ignore the variability in children's cognitive development, behaviours and the contextual variables that influence the situated use of interactive products for children. Further reflections stress the need to move beyond the evaluation of only cognitive aspects in order to encompass the wider range of human resources included in meaning-making processes (Jewitt, 2013). Malinverni and Pares (2014a) point towards a lack of user involvement in the early stages of the design process and a general scarcity of embodied design techniques for children. In summary, these limitations point towards a general need for research efforts on novel approaches for Full-Body Interaction design methodologies.

Inspiration for novel strategies can be found in related research areas of other embodied interaction technologies that use the "lived body" as a steering motor to understand and design for the user experience.

\subsection{Embodied Design Methods}

The role of the body has become the key to design ideation across a wide range of research fields in $\mathrm{HCl}$, such as tangible interaction, wearables, virtual, augmented and mixed realities, the Internet of Things, etc. (Wilde et al., 2017). Several scholars use somatic practices such as Feldenkrais, Mindfulness, Dance and Somaesthetics (Höök et al., 2016) to develop theories and practices around movement qualities and experiential artefacts. Françoise et al. (2017) stressed the importance of kinaesthetic awareness in embodied design to understand the subjective experience of the user. Alaoui $(2015,2012)$ focused on movement qualities during dance performance. Höök (2010), in an autoethnographic study, researched the qualities of horseback riding. The aim was to provide knowledge for the design of digital technology that is grounded on fostering physical experience; e.g. rhythm, balance, link movement, and emotion. Loke and Robertson (2010), in collaboration with trained dancers, studied the qualities of the act of falling. The goal of their research was to understand the first-person experience and external representations of the movement for the design of motion-sensing technologies. These strategies challenge the WIMP approach by focusing on deeply embodied characteristics of human motion in design.

On the other hand, many designers derive their practices from performance methods, for instance, lacucci et al. (2002) use situated scenarios to envision new ideas. Giaccardi et al. (2012) employ a technique based on embodied narratives using Polaroid PoGo instant digital cameras to collect ideas. Furthermore, in their research a number of scholars demonstrate the benefits of bodystorming in the form of role-play (lacucci et al., 2000; Márquez Segura et al., 2016; Simsarian, 2003) as an effective design and evaluation method in human-centred design workshops. The outcomes confirmed that this technique facilitates effective design 
solutions, helps end users to reflect upon their own behaviour, and allows the users' views to be incorporated in the design process. Other scholars explored using small-scale representations of humans and design elements. For instance, Lerdahl et al. (2002) proposed a technique using objects that represent users and objects. This approach has been seen to provide participants with a contextual perspective in the task design. lacucci et al. (2000) investigated the use of toy characters and role-play as objects for confronting challenges in the design of mobile services and devices. They reported that role games using toy characters and contextual and environmental representations provided a platform that helped in the process followed by players to envision and enact new mobile product concepts. In this context, Lim et al. (2006) argued that the material used in prototypes has a direct impact on users' perceptions when it is used for evaluating a design concept and usability issues. Based on this framework, different materials and objects have been explored to represent users in the design process, such as paper silhouettes and Ludo tokens (Jakobsen, 2012), pieces of foam (Brandt and Grunnet, 2000) and Lego characters (Pedersen and Buur, 2000). This approach provides participants with a bird-perspective on use situations and enables them to explore and discuss simultaneous acts of different represented users (Jakobsen, 2012).

Other designers focus on elicitation techniques for physical actions (Connell et al., 2013; Malinverni et al., 2016c). For instance, Connell et al. (2013) used the Wizard of Oz approach to elicit children's gestures for object manipulation, navigation-based tasks, and spatial interaction. Wobbrock et al. (2009) suggested that often, user-generated gestures are easier for the user to handle than those defined by the designers only. These physical actions must be essentially automatically executed and not rely on the conscious step-by-step learning of a pre-defined gesture grammar (Antle et al., 2009; Pietroni et al., 2012).

Despite this broad panorama of embodied design methods, in the Child-Computer Interaction community, only some embodied interaction research studies have explored their benefits when working with children. For instance, one example of using performance methods is the StoryRooms (Alborzi et al., 2000) project in which designers explored the benefits of bodystorming. During the workshop, children and other members of the design team enacted possible sensors, actuators, and the interactive system by using their bodies, spotlights and other low-tech material.

Other scholars have researched the benefits of elicitation techniques with children. For instance, Höysniemi et al. (2005) used Wizard of Oz (WOz) prototyping to evaluate testing the intuitiveness of game mechanics. In this project, children could control an avatar which had to run, jump or swim. The authors used the WOz method to simulate the playing experience and asked the children to imagine and perform the physical actions that they thought were best to control the avatar. Landry et al. (2012) used a similar Participatory Design and WOz approach to analyse the types of movements which children would enact while playing in the Interactive Slide platform (Soler-Adillon, 2009). An important aim of this study was to draw children's attention to the physical potential of the slide within an interactive experience and to help them adapt their interaction design ideas to these specific qualities.

These latter examples provide first attempts to understand children's felt-experience with a Full-Body Interaction prototype. However, we claim that further research is required to go 
deeper into strategies that promote children's embodied awareness and ideation for the specific qualities of Full-Body Interaction and their embodied experiences.

\subsection{Multimodal Analysis to understand the Embodied Experience}

Research in the Child-Computer Interaction community stresses the importance of children's participation during technology design activities to ensure that they support them in ways that "make sense for them as young learners, explorers, and avid technology users" (Druin, 2002). On the other hand, scholars have shown how co-design workshops, particularly, provide opportunities for the direct observation of children's embodied meaning-making (Malinverni et al., 2016b). However, to properly collect and understand these latter aspects, it is necessary to go beyond the analysis of only explicit verbal feedback or usability issues. At the same time, designers need to tackle the challenge that children express themselves differently than adults. Multimodal Analysis is another interdisciplinary approach to collect, analyse and interpret the multiple resources (e.g. body postures, spatial interaction, facial expressions, gaze, verbal expressions, drawings, etc.) that children employ during the activities. This research method proposes an analytical lens to understand how users employ different modes to construct and express meaning (Malinverni et al., 2018). Multimodal Analysis is derived from socio-semiotics and focuses on communication and situated interaction from a perspective that goes beyond the limit of verbal language and encompasses the different resources that people use to construct meaning (Jewitt, 2013). On a theoretical level, it is grounded on the key concept of mode, which constitutes a set of socially and culturally shaped resources for making meaning, e.g., the ensemble of writing and images on a page (Jewitt, 2013). According to this framework, each mode has a set of modal affordances, which refers to 'what is possible to express, represent or communicate easily with the resources of a mode and what is less straightforward or even impossible' (Kress, 2010). Its application in research on embodied interaction has proved suitable to analyse and understand user interaction in highly multimodal experiences (Price et al., 2015; Price and Jewitt, 2013; Van Mechelen et al., 2016). Its application in the analysis of codesign activities for Full-Body Interaction can offer relevant contributions to observe and analyse the meanings that are constructed through the different modes offered during these activities.

\subsection{Co-Design Practices in Child-Computer Interaction}

Involving children in the co-design of embodied technologies requires providing a common view on their participation and role as designers. This view guides the design team through a process of collaboration, felt-experiences, exploration of ideas, decision making and critical reflection of the project outcomes. In general, user involvement in $\mathrm{HCl}$ research is grounded on theories derived from cooperative design (Bødker et al. 1988), participatory design (Schuler and Namioka, 1993; Simonsen and Robertson, 2013), and contextual inquiry (Beyer and Holtzblatt 1998), among others. However, there is no unified view of how user participation should take place (Muller and Druin, 2010). Each framework implies different underlying values and assumptions about stakeholders' roles and agency in the design process.

Participatory Design originates from the Scandinavian countries. Its theoretical perspective and epistemology imply understanding Participatory Design as "a different way of knowing" (Frauenberger et al., 2015), i.e., designers need to evaluate why and what they want to know about a product or experience. This process of knowing is directly connected to participation and practice. In the early stages of the emergence of Participatory Design, users were 
involved to understand their use of technologies and how they affected their lives (livari et al. 2015). Later, the participation of both adult and child users was extended to roles such as design partners, informants, and testers (Nesset and Large 2004). Each of these roles has its own function, depending on project resources, designers' philosophy and intentions. The role of "design partners" arises from the idea that every stakeholder contributes with their own expertise during the design process (Druin, 1999). This starting point breaks traditional power hierarchies between experts and users as well as between adults and children. Building on this, Yip et al. (2017) proposed a framework that examines the complementary roles between children and adults. These scholars argue that adult-child partnerships in design processes are often composed of four main dimensions: (1) facilitation, which refers to how much support and mediation takes place between the adults and children; (2) relationship building, which refers to how much social interaction occurs in the co-design group; (3) design-by doing, which refers to moments when design activities (such as prototyping, evaluation, etc.) take place, and (4) elaboration, which refers to how adults and children exchange and generate ideas together. The framework shows that defining the roles of adult-child partners in co-design as "balanced" or "unbalanced" is not an easy task. Each dimension has moments when participants dominate the design task or work collaboratively, i.e., the role of each partner and the range of interactions between each other can vary between individuals, groups and even between sessions.

Other approaches situate their view of the child-designer relationship between the usercentred and participatory perspective, following an informant design model (Scaife and Rogers, 1998). During informant design, designers tend to involve children at stages in which they consider children's input as appropriate and critical (Walsh et al., 2013). However, this approach has been criticized for taking the risk that only designers make the core design decisions (Iversen and Dindler, 2013) and that children's participation may "become decoration" (livari et al., 2015). To prevent this hazard, Read et al. (2002) proposed the IBF Participatory Continuum Model that distinguishes between design experts (academics) and domain experts (children and/or adult helpers). According to Read et al. (2002), the participation of domain experts in the informant design model is mainly limited to informing the design experts without any further agency. In contrast, the balance design approach targets an equal partnership between design experts and domain experts, and in the facilitated design approach, the domain experts are supported by design experts to implement their ideas.

From the standpoint of the original Scandinavian approach, Participatory Design embraces three political ideals: democracy, emancipation, and skilfulness (Iversen and Dindler, 2013). In practice, these underlying values shape the dialogue between stakeholders and designers and the design methods that are employed. However, when designing with and for children, there has been no tradition of an explicit consideration of these core values to guide design projects (Yarosh et al., 2011). Therefore, recent design efforts in Child-Computer Interaction are increasingly focusing on how to improve dialogue and symbiotic agreement (Dindler and Iversen, 2014) in design teams. For instance, Frauenberger et al. (2015) proposed a "tool-tothink-with" to enhance the notion of accountability and rigour in the design process. They specifically aim to encourage design practitioners to reflect upon the collaborative work in a design team, decision making and outcomes in a transparent way. Building on this work, Van Mechelen et al. (2016) proposed the GLID method to increase internal rigour and transparency in co-design practices and go beyond the surface level of ideas by identifying participants' values embedded in design outcomes. Furthermore, Iversen at al. (2017) 
claimed that a commitment to political participatory design requires the definition of a new role for children in participatory practices - the role of protagonist. This role implies not only giving children a voice in the design process - or letting them act as co-designers, but also empowering them adequately to influence technological development and critical reflection on the role of technology in their lives.

However, none of these co-design strategies has specifically focused on methods and techniques that allow participants to explore, reflect or incorporate the notion of the body in their design proposals. We aim to close this research gap by proposing an approach that responds to the current design efforts in Child-Computer Interaction and Full-Body Interaction design by focusing particularly on the question "how can we engage children and their bodies in co-design processes?". At the same time, we aim to enhance the collaborative work within design teams.

\section{FUBImethod}

The FUBImethod that we describe in this paper proposes a set of clearly defined steps to help co-designers in guiding intergenerational teams (interaction designers, teachers, topic experts, etc.) with children to understand the role of the body in a Full-Body Interaction experience, to make a justified use of Full-Body Interaction and make the most of its properties. The stages make co-designers raise their awareness of their bodies and of space. They also help co-designers in the process of translating the properties of Full-Body Interaction into concrete design ideas and of exploring them in different prototype iterations. We decided to present the FUBlmethod through multiple projects to illustrate different scenarios of its application in Full-Body Interaction. These strategies are explained and contextualized within real projects that we have developed in the research project "Evaluation-Driven Design". The goal of this project was oriented towards the exploration and definition of adequate research methods for Full-Body Interaction Learning Environments (FUBILEs). We believe that these strategies provide excellent results, however, they are by no means the only possible strategies for use at each stage and we invite designers and researchers to add new ones. Therefore, the six stages of the FUBImethod act as a container that provides a conceptual structure for designing Full-Body interactive experiences. On the other hand, we stress that this paper is not an attempt to validate the FUBImethod because it will be clearly validated through its use in time. We propose the method and its stages as a sequence of steps and strategies to co-design Full-Body interactive experiences. Our aim is to share the specific advantages that this process has shown with the $\mathrm{HCl}$ community and support the results through our experience in applying the design stages in a number of projects.

The method is situated between the Informant Design and Participatory Design model. In other words, the design team decides when the involvement of each stakeholder is appropriate according to the needs of the specific project (Scaife et al., 1997). There are numerous ways to include stakeholders as informants in the design process. Usually, the role of informant implies observing stakeholders' actions and listening to their feedback during the design activities. Our method differs from the original Informant Design approach by focusing on the expertise that stakeholders (Dindler and Iversen, 2014) can bring into the design process and on a mutual learning approach between adults and children. 
On the one hand, children benefit from adults' expertise in design, knowledge of the design context (e.g., topic related to natural science, cultural heritage, arts, etc.) and somatic practices (physical theatre, yoga, Feldenkrais, etc.). On the other, the method builds on the notion of children's skilfulness (Iversen and Dindler, 2013) in Full-Body Interaction design, i.e., young designers can contribute with a different perspective of using the body (i.e. playfulness and natural movement). Furthermore, we particularly concentrate on providing adequate design techniques that allow children to fully participate in the design process (Iversen and Dindler, 2013). This participation can imply both indirect involvement, through observations of children's behaviours, or direct involvement, through design activities aimed at defining design proposals and evaluating prototypes.

For the development and definition of our approach, Mathiassen's work (1998) on "theories and method for system development" has provided us with useful guidelines to structure the theoretical framework of the FUBImethod. From Mathiassen's perspective, a method is limited to a specific application area. In our research, we focus on the exploration of the potential of Full-Body interactive experiences for children. Furthermore, Mathiassen stresses that a design method also defines a general perspective on a phenomenon as well as an underlying theory of system development. Our research focuses, on the one hand, on the need to include children in interaction design, and is based on assumptions of embodied cognition theories. According to Mathiassen, this perspective frames the principles of organization that characterize a co-design process and which tools and techniques the design team decides to employ.

Building on Mathiassen's perspective, the FUBlmethod is organized in six design stages as follows: (1) Defining a Common Ground, (2) Defining Context and Goal Appropriateness (3) Awakening Embodied Awareness, (4) Translating Embodied Experience, (5) Prototyping Embodied Experience and (6) Understanding Embodied Experience (Figure 1).

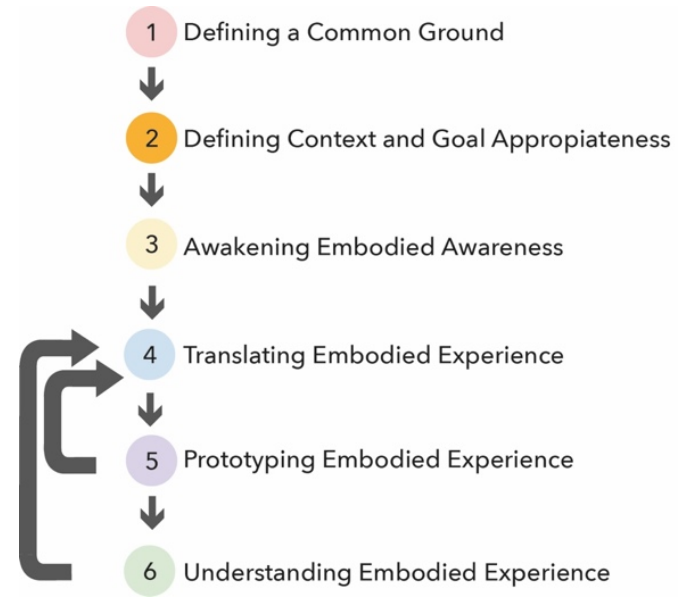

Figure 1: FUBImethod overview

We will now illustrate how the FUBImethod may be employed using the outcomes of a number of design examples.

\section{Defining a common ground for participation within the network}

3.1.1 What does this design stage involve? 
This design stage aims to establish the participation of the co-design team within the network. Therefore, each member needs to reflect upon their own lenses for personal interests, values and commitment level in the project. It is important to note that this stage is the foundation of co-design projects in general and not only relevant in Full-Body Interaction design. The final goal is to achieve symbiotic agreement (Dindler and Iversen, 2014), i.e., relationships based on mutual accords among co-designers where symbiosis is understood as a state "in which every protagonist is interested in the success of the other for its own reasons" (Edwards, 2010). We focused our research particularly on emerging values that concern the agreement on children's roles and participation throughout the design process.

\subsubsection{Why is this design stage important?}

Muller and Druin (2010) describe co-design as a third space that helps build bridges to convey knowledge and practices between researchers, developers and end-users. Thus, the concept of symbiotic agreement can help balance each stakeholder's professional knowledge and reach a consensus on values and power relations within the design team. This approach can promote the capacity for mutual learning, negotiation of assumptions and shared construction of the design between the particpants. Furthermore, it increases commitment and ownership of the evolving knowledge and design within the team. In design projects with children, these aspects are relevant because they help to engage them in the design activities and leverage the expertise they can contribute to the design. According to Makhaeva et al. (2016), this project stage can also be reflected in the concept of a Handlungsspielraum, the creative space in which the co-design team collaborates, and predefined structures and freedoms in the design process are explored. Thus, the Handlungsspielraum defines the role of each co-designer and which research methods are employed.

\subsubsection{How has this design stage been employed in practice?}

In this design stage, we propose approaches that allow (1) researching co-designers' values and assumptions on children's roles in the design process and (2) employing strategies that facilitate an open dialogue on the values of children's participation. In practice, we addressed these goals in the project Refugi 307 (Schaper et al., 2018a). Its main goal was to design an educational experience of a Spanish Civil War shelter that would complement the traditional guided visit to it (Figure 2). In the first design stage of this project, we focused on the analysis of different viewpoints of the stakeholders in order to define new strategies that could balance the power relations between adults and children (Schaper et al., 2018b).

Researching co-designers' values and assumptions requires the use of methods that permit a critical reflection upon the design process. In this project, we used Critical Discourse Analysis (van Dijk, 1993) to compare stakeholders' expectations at the start of the project. Scholars (livari et al., 2015) in the field of $\mathrm{HCl}$ have employed this method to analyse power relations and domination in socio-political contexts, e.g., between different "actors" in the design process. These structures are commonly expressed through statements (e.g., in the form of language, drawings or technological artefacts (Spiel et al., 2016)). In our study, we focused on stakeholders' oral and written contributions. Our analysis started by carefully reading the data archive described above. Potential statements were extracted using NVivo11 software and synthesized into one document. To facilitate the comparison of viewpoints, we kept the statements of each stakeholder group (museum experts, teachers, designers, and children) in a separate column. We reviewed the data and coded the statements according to repeated concepts that reflected stakeholders' ideologies. We 
detected the repeated concepts as follows: (1) co-designers' cultural values related to childhood (solidarity, respect, empathy, identity, enjoyment, ignorance, incompetence and influenceability), and (2) their expectations of children's role and agency in the design of the educational experience (empowerment, co-creators, active participation, informants, guided learning, collaborative learning, educator-controlled learning). Two design experts then discussed and compared the discourses produced which were grounded on co-designers' ideologies and attitudes expressed in the statements.

Finally, we wished to reveal a general outline of differences in the discourses of the codesigners relating to childhood and children's role in the design process. To achieve this, we categorized the outcomes according to a theoretical framework that represents a discursive construction of the concept of childhood. This framework was originally proposed by James, Jenks and Prout (James et al., 1998) through which they identified the following categories: the evil child, the innocent child, the immanent child, the naturally developing child, and the unconscious child. This framework was further developed by Skovbjerg and Bekker (Skovbjerg et al., 2016), who adapted it as a card tool called CHIld PerspectiveS In Design (CHIPS) to work with values on children's roles in design.

In this project, we discussed and contrasted the different viewpoints of three design experts, one curator, one museum educator, three guides, four teachers, and 40 children (girls = 18; boys $=22$; mean age $=10.78$ years). Our findings showed that the underlying assumptions of adult co-designers, as well as their expectations of children's design skills and roles in the design process were strongly influenced by different concepts of views on childhood. More specifically, we detected major differences between the expectations of the design and field experts. In a sense, the field experts believed that children should only "learn from us" whereas the design experts also assumed that we could "learn from children". The museum's design practices for guided visits and learning materials were grounded on a topdown model based on content-driven strategies. Conversely, the design experts considered the analysis of children's interests and behaviour as the starting point for the design process.

Subsequently, we, as design experts, guided the agreement process and defined strategies aimed at facilitating negotiations through open dialogue between different viewpoints and objectives among the co-designers. On the one hand, we proposed involving field experts in future design sessions with the children. We assumed that this procedure could give the field experts the opportunity to observe children's participation and to better value their contributions as potential design partners. On the other hand, we proposed interviewing them directly about their own involvement and experience during the workshops. This procedure may motivate children to participate in the design process because they feel that their opinions are as valued as those given by adult co-designers.

Building on our experiences in this project, we recommend employing methods based on Critical Discourse Analysis to detect frictions in co-designers' assumptions on values and roles throughout the project. It is also important to note that values and roles are continuously evolving and being redefined during the design process. The approach directs, among other aspects, decision-making processes on how goals and expectations should be communicated between co-designers, but also determines the choice of methods and techniques used during co-design workshops.

\subsubsection{Which risks and limitations does this technique involve?}


The proposed strategies would certainly make demands on the field experts because they require the capacity for being open-minded, to recognize and adequately respond to what others might offer. Edwards (2010) highlighted that the rejection of new ideas through collaborating with other professionals is more likely to occur in workplaces that are bound together by the bureaucratization of professional practices and embedded in routines than in organizations that are driven by the co-production of solutions, such as software engineering. Our results showed that curators in museums and cultural heritage sites were primed by conservative approaches of defining educational experiences and working practices. Iversen and Dindler (2013) stress that these dilemmas can be overcome by proposing appropriate methods as a springboard to help stakeholders to reimagine and re-engage with their values. Therefore, we believe that in this project, we need to make a greater effort in mediating codesigners' comprehension related to the need for shared agency. This process requires codesigners to acknowledge the benefits that may result from the common knowledge built up between the design team members, specifically the knowledge children can bring into the design process.
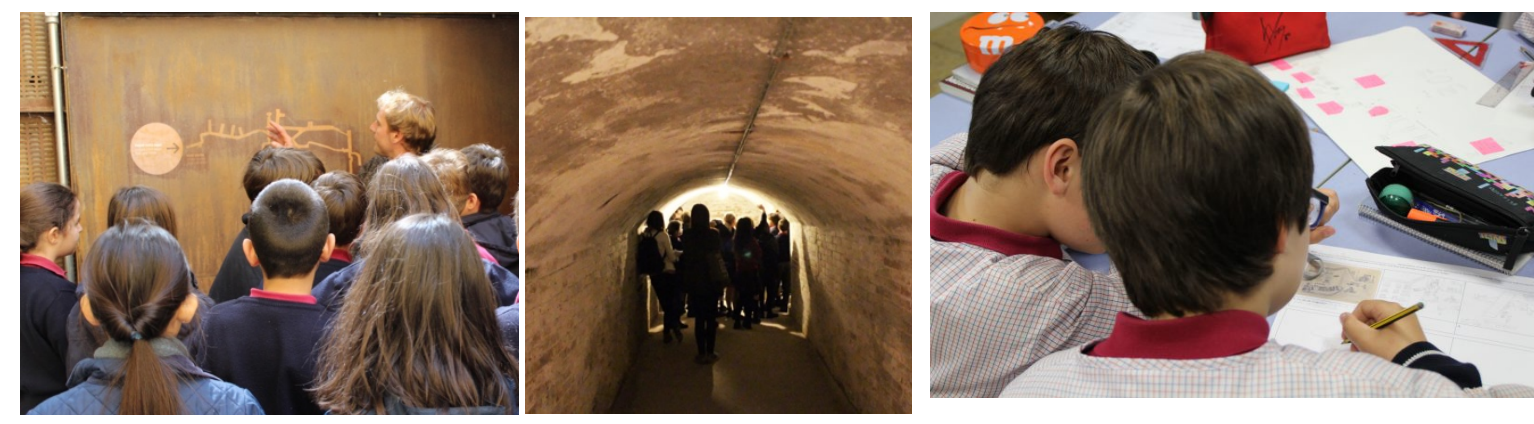

Figure 2. Left and centre: A school class during a guided visit to the Spanish Civial War shelter "Refugi 307". Right: Two children during the co-design workshop in class filling out a storyboard with a possible narrative for the guided visit.

\subsection{Defining context and goal appropriateness}

\subsubsection{What does this design stage involve?}

The goal of this design stage addresses two fundamental challenges outlined in the introduction of this paper. First, the co-design team needs to define an educational context and contents that are aligned with children's knowledge, interests, understanding and sociocultural values. A second design challenge concerns the need to question the goal appropriateness (Malinverni and Pares, 2017) of the employed medium, i.e., whether FullBody Interaction is the best design solution to support the defined design or learning goals (Malinverni and Pares, 2014b). This notion builds on the contribution of media theory (McLuhan, 1964) and multimodal social semiotics (Van Leeuwen, 2004). According to McLuhan (1964), all media are active metaphors which have the power to translate and transform experiences into new forms. As a consequence, each medium constitutes itself a message (Levinson, 1993) since it conveys specific meanings and shapes perceptions through its features. These features delineate a panorama where each medium can be more or less appropriate to convey specific meanings or support specific experiences. In the context of FUBILEs, this implies that designers should carefully understand the specificities of Full-Body Interaction in order to define the goals and experiences that can be better supported by this medium. 


\subsubsection{Why is this design stage important?}

In this stage, the co-design team evaluates if the project goals are appropriate for children as a target group. This first step is essential for the design process because it allows, for instance, identifying children's knowledge gaps that can be addressed as learning goals. Furthermore, it can inform the design team about potential concepts that can bridge the gap between what children already know and novel knowledge, i.e., children's previous knowledge can be used as an entry path for the comprehension of novel learning contents (Rogoff, 1998). For this reason, children's participation is required to research their perspective on the context and contents. The outcomes of this requirement gathering determine if a project continues or if changes are required in the focus of the design goals. Moreover, in this step, co-designers examine if the concept of Full-Body Interaction is the best way to convey the design contents or if a different medium may be more adequate.

\subsubsection{How has this design stage been employed in practice?}

In this design stage, we propose using design techniques that allow researching (1) children's worldviews on the learning context, and (2) what the concept of Full-Body Interaction can add to the educational experience. To combine these aspects in a single approach, we proposed the Dwelling Space Technique. The use of the technique allowed us, on the one hand, to understand children's worldviews in relation to an educational context. On the other hand, we were able to observe how the children became bodily engaged with a specific physical space. These aspects helped us to understand how Full-Body Interaction could contribute to an improvement of the learning experience. We explored the potential of the technique within the project Refugi 307 (Schaper et al., 2018a). Twenty children (14 girls; 6 boys; mean age $=10.7$ years) participated in the study. First, the children joined a guided visit through Refugi 307 (90 minutes). Subsequently, for the Dwelling Space Technique, they were randomly divided into groups of four. To debrief the children, we used the KidReporter method (Bekker et al., 2003) that proposes a playful activity for children in which they investigate a specific topic by pretending to be a journalist of a newspaper team. In our project, each group received a map of the shelter and was asked to choose the place that had caught their attention the most. The children were then instructed to imagine that they were recording a report on Refugi 307 for a local TV channel. Each child was randomly assigned a role and asked to act as a reporter, a cameraman or an interviewee. We gave each group 10 minutes to choose one place of interest and to brainstorm how they would perform the interview. The children carried out the activity inside the actual cultural heritage site. The groups entered the shelter again accompanied by two adults. They were encouraged to go to the place of their choice and to record a short video of approximately two minutes about why their group chose that place and what made it the most interesting part of the shelter for them (Figure 3, left). A day later, we conducted a workshop in school (60 min) during which the children were asked to propose a redesign of the guided visit. The children worked in the same groups as during the first session. They first brainstormed ideas within the group, wrote their main ideas down and presented them later to the entire class (Figure 3, right). The brainstorming and presentation were video-recorded and analysed following our multimodal methodological approach. We will explain its procedure in more detail in Section 3.6.3.

The results of the study revealed how being situated in the physical space during the Dwelling Space Technique primed children's interests expressed in the interviews and contributions for the redesign activity. The interviews showed that they were particularly interested in how the characteristics of the physical space had an impact on people's 
experiences in the shelter. For instance, the children mentioned that the rounded finish of the walls around corners facilitated the transport of injured people on stretchers. During the redesign activity, the children proposed possible enactments within the physical space, e.g., using a pickaxe and a shovel to construct new parts of the tunnel and discover hidden aspects in the cultural heritage site. Thus, we decided to include activities in the guided visit based on children's proposals for enactments. We assumed that these activities would allow children to "embody" actions from the past (Flynn, 2013) and better empathize with Spanish war civilians who helped to build the shelter. By performing the same actions as these people, they could perceive the notion of the physical effort (Lyons et al., 2012) that civilians made to save their lives and those of others.

Building on our experiences in this project, we recommend employing design techniques in the first design stages that allow researching both children's worldviews on the educational context and the appropriateness of the interaction concept that designers envision. In this project, the definition of the context was led by the design and field experts. Nevertheless, depending on the project requirements, it is also likely that children will be involved in the decision-making process of this aspect. Finally, we conclude that the technique is applicable to other research contexts related to the design of child experiences and site-specific locations. The activity helped to overcome different levels of children's verbal expression because they could include visual clues and body language. This allowed the co-designers to assess children's contributions on a multimodal level.
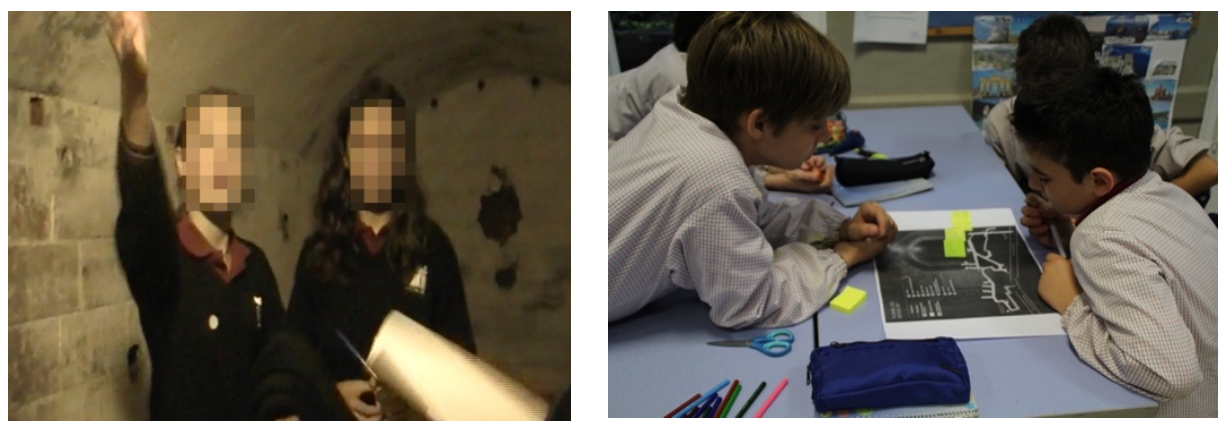

Figure 3. Left: A group explaining its interest in the medical room in the shelter). Right: A group brainstorming ideas for the redesign of the guided visit.

\subsubsection{Which risks and limitations does this technique involve?}

We argue that the technique could be more effective if the redesign activity were be conducted on site. This procedure would allow the children to explore different aspects of their proposals motivated by their own interests and leave them more time for discovering new aspects of the learning content at their own pace. In the study presented, we focused on observing children's interpretations and listening to their design proposals around the educational context. However, the definition of the concrete activities for the interactive experience was only made by the adults in the co-design team. This procedure risks the children's preferences coming into conflict with the pedagogical goals (Scaife and Rogers, 1998) and, thus, be misinterpreted or even neglected.

\subsection{Awakening embodied awareness to understand FUBI features}

\subsubsection{What does this design stage involve?}


The goal of this design stage is to introduce the co-design team to the fundamental qualities of Full-Body Interaction and to understand the features of the embodied child experience. Therefore, we propose to organize workshop sessions that involve embodied exercises aimed to make co-designers aware of sensations related to their own body and to communicate them to other members of the team. In our research, we focus on embodied techniques that allow engaging both adults and children in the design activities and promote a mutual learning approach between them. Additionally, we recommend deepening this feltexperience by facilitating exercises that promote awareness about how the body relates to spatial and social aspects between people and the environment. The final goal of this design stage is to get all co-designers of the team to understand these embodied qualities as tools to generate meaning around the project context and train them in different ways to "bodystorm" design ideas.

\subsubsection{Why is this design stage important?}

Due to the imprinting effect of our Cartesian Western culture (Kelan, 2010), people tend not to be trained to intentionally use their body as an expressive medium. As a consequence, while bodystorming approaches have proved to be particularly fruitful with trained practitioners such as dancers or performers (Loke, Robertson and Sydney, 2013), they may prove challenging to the general population. On the other hand, particularly in the design of technologies for younger users, adults may benefit from children's perspective on the body and natural playfulness. Therefore, in our research we focus on embodied techniques that allow engaging both adults and children in the design activities and promote a mutual learning approach between them.

\subsubsection{How has this design stage been employed in practice?}

In this design stage, we propose using embodied design techniques that allow (1) codesigners to become bodily engaged to explore the properties of Full-Body Interaction, and (2) leveraging children's perspective of the body. To address these challenges, we decided to explore the potential of embodied elicitation techniques based on physical theatre play within the project Magical Movements (Schaper and Pares, 2016). The main goal of the project was, in collaboration with twelve students (4 girls and 8 boys) between 10 and 12 years and two teachers from the local theatre school Plàudite - Arts Escèniques de Proximitat, to co-design a novel approach to integrate a storytelling experience in theatre events. The co-design workshops focused on children's worldviews in relation to Shakespeare's play A Midsummer Night's Dream and led to the definition of content, visual and interaction design ideas for a first design iteration of a Full-Body interactive experience. During one workshop session, we introduced the students to an embodied co-design activity based on collaborative performance and gestures, titled Situated Bodystorming Technique. The technique is a bodystorming activity based on the physical theatre exercise "the machine of rhythms" (Boal, 1992). We started with one child performing simple, repetitive movements of their choice, related to the space and idea chosen by their team. The other children joined in the exercise one after the other with a complementary movement. In this exercise, we particularly encouraged the children to explore their physical actions in different locations and to incorporate the space which surrounded their bodies in their proposals.

For the technique, the students were divided into small teams of four members. First, each group brainstormed a narrative related to the concept of "magic" and defined a physical location in the theatre school that represented their main idea. They were then asked to perform their proposal of the narrative using the technique. The theatre teachers helped us to correctly instruct the exercise and particularly encouraged them to incorporate the space 
which surrounded their bodies in their proposals. Therefore, we asked each group to perform the exercise first in the workshop room (Figure 4, left), then in the location in the theatre school that they had chosen (Figure 4, right), and finally again in a group presentation in the workshop room. The children's activity during the co-design session was video-recorded and analysed following our multimodal methodological approach (see Section 3.6.3).

Our results showed that the technique allowed the children to explore sensations of movement variations. By slowing down the pace of the movement, it became clearer to them how various parts of the body interacted in the process of moving. Repeated movements helped the children to keep their focus on the sensorial experience in relation to the situated environment to compare sensations that they had imagined before their performance. Enacting the physical actions in different locations helped them to explore questions of person-space interactions (e.g., timing, coordinating and synchronizing body actions) and led to understanding related to the capacity and constraints of body actions. Performing these actions with their own bodies also allowed them to explore and become aware of the effects of inter-relating movements between the different actors from an internal perspective. Furthermore, the children paid attention to the movement of other actors sharing the same action space. Finally, this technique was useful to train the children in using their body as an expressive medium and to understand features that are relevant in Full-Body Interaction design.

Building on our experiences in this project, we recommend employing playful design techniques that engage children in bodystorming activities and allow them to reflect upon their body sensations and relationships between proxemics.
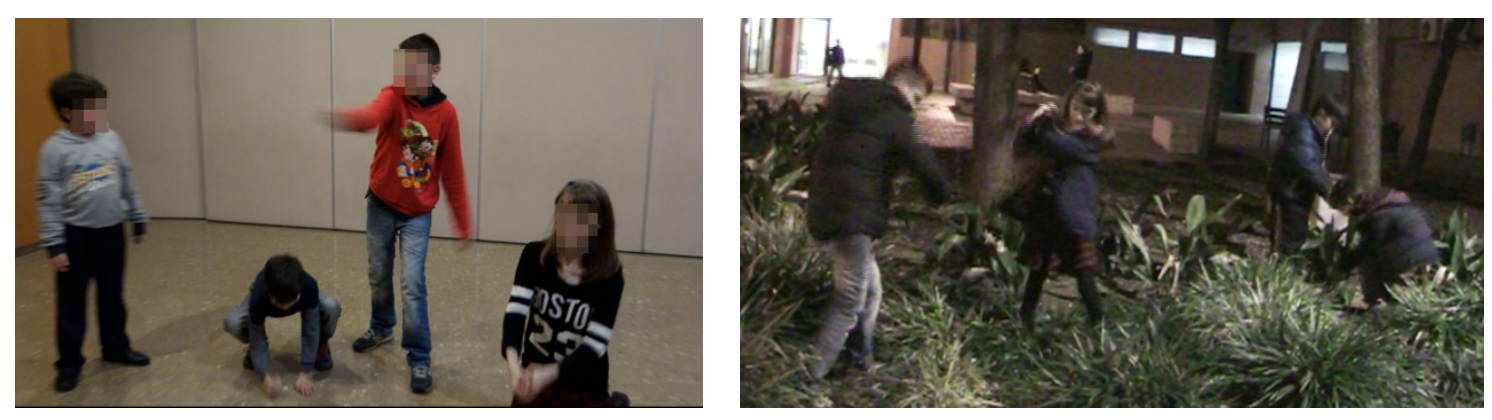

Figure 4: Left: The students performed the concept of a magical garden. Therefore, they enacted different actions such as hoeing, harvesting, and watering in the workshop room, and Right: repeated their performance in the physical location that represented their core idea of the narrative.

\subsubsection{Which risks and limitations does this technique involve?}

Our results were mainly based on design experts' observations during the activity. In future projects, it would be advisable for adult co-designers to also experience the same body exercises to gain a better understanding of the felt-experience. One possibility would be for the children to instruct the adults in performing movements that transmit body sensations from a child's perspective. In this procedure, it would also be important to stimulate conversations between all co-designers about the different sensations that they experience during the exercises. On the other hand, the instruction of the exercise required the help of professional theatre teachers. This finding suggests that at least one co-designer in the team needs to be sufficiently trained in the technique used during the workshop. Another solution would be to incorporate practitioners (e.g. physical theatre, somatic practices, etc.) in the co- 
design team and accompany those design stages which requiring their expertise. Furthermore, this technique has only be explored with children who had previously been trained in physical theatre practice. To make robust conclusions on the benefits of the technique, future studies also need to research its potential in projects with children and adults of the general population.

\subsection{Translating embodied experience into co-design ideas}

\subsubsection{What does this design stage involve?}

The aim of this design stage is to instruct the co-design team in how they can use their feltexperience and knowledge in embodied awareness to define concrete design ideas for an interactive prototype. It also aims to overcome legacy bias caused by users' experience with traditional WIMP and touchscreen interfaces (Ringel Morris et al., 2014). These deficiencies have often been reported using gesture elicitation techniques for the design of Full-Body interactive technologies (Hoff et al., 2016; Ringel Morris et al., 2014; Schaper et al., 2014). In these contexts, users may tend to propose gestures that mainly emulate simple touch or mouse-based interaction and do not incorporate the potential of Full-Body interfaces.

\subsubsection{Why is this design stage important?}

In the previous stage, the co-designers are trained in embodied awareness. This notion entails non-verbal knowledge about embodiment and how sensations evoked through movement can mediate an experience. In this step, we address the third design challenge that was highlighted in the introduction. This challenge refers to the need to develop methods that facilitate designing for and with the body. Thus, we propose using techniques that allow translating this knowledge into tangible design ideas, i.e., this translation permits transforming a feeling, sensation or idea into "a product" that can be experienced by others, evaluated and redefined. Furthermore, we claim that in this design stage, children can particularly contribute to design ideation due to their playful way of approaching and expressing ideas. More importantly, they are the actual experts in understanding the child experience that is designed for them as the target group.

\subsubsection{How has this design stage been employed in practice?}

In this design stage, we propose employing techniques that (1) use the felt-experience to think of concrete interaction design ideas, (2) focus on situatedness (i.e., use the body in space to make meaning), and (3) promote reflection upon social relationships (i.e., use proxemics in the space with others to make meaning). Building on previous work on design techniques with children, we decided to take advantage of their specific play patterns and behaviours. Most children are familiar with puppet play. We assumed that using puppets as design instruments for physical actions would allow, and additionally motivate, children to actively participate in the design process. Furthermore, we believed that this approach could allow children to express their ideas at different levels, through verbal articulation and through play, for instance.

The potential of the Puppet-Based Design Technique was first explored in the Ecosystem Project (Schaper et al., 2015). The goal of the study was to enable children to design specific body actions of a FUBILE, aimed at supporting children's understanding of environmental issues related to air-pollution. The study involved the participation of nine children ( 5 girls and 4 boys) between 10 and 11 years of age from a local school. At the beginning of the session, the children first had the opportunity to interact with a mid-fidelity 
prototype of the FUBILE. The purpose of this activity was to familiarize the children with the learning environment. In the subsequent workshop, they were encouraged to think of different interaction ideas using the Puppet-Based Design Technique. Therefore, we asked the children to think of gestures and movements which would show reciprocal relationships between specific game elements, i.e., they were instructed to propose ideas which would emphasize the relationship between wind energy and the energy consumption of a city, as well as the relationship between plants and compost. We showed them a diagram depicting the reciprocal relationships between the different elements (Figure 5, left), asked them how these elements were related, and wrote the correct answers on a white board. The children were then randomly divided into three groups and instructed in using the flexible anthropomorphic puppets (Figure 5, right). After this, we provided them with cameras and asked them to record videos of their ideas. Finally, each group presented its design solutions to their peers and the design experts. The session was video-recorded and analysed following our multimodal methodological approach (see Section 3.6.3).

Our results showed that the children constantly switched between two modes, using the puppets and then performing their interaction design ideas with their bodies. This continuity of shifting from one mode to the other mainly occurred when the children aimed to bodily explore their own ideas or those proposed by their peers. This repetitive play rhythm seemed to allow the children to focus on what matters in the design task and to think of different solutions for physical actions. Furthermore, the technique allowed the children to express an idea through multimodal resources, verbally through doll play, and bodily, while they were enacting their ideas.

Building on our experiences in this project, we recommend employing playful design techniques that generate a balance between "getting immersed in a situation" and "stepping back" from it in order to construct knowledge and learn (Ackermann, 2004). This procedure has been seen to allow the children to focus on both the ideation of new ideas that are suitable for Full-Body Interaction and the felt-experience of these body actions.

\subsubsection{Which risks and limitations does this technique involve?}

The use of puppets may not be adequate for older children and adult co-designers. Thus, the co-design team needs to provide techniques that evoke similar behaviour of immersion and reflection on the embodied experience. In future projects, it would be advisable using techniques that allow co-designers to explore ways in which the notions of situatedness and social relations play a role in the ideation of the interactive experience.
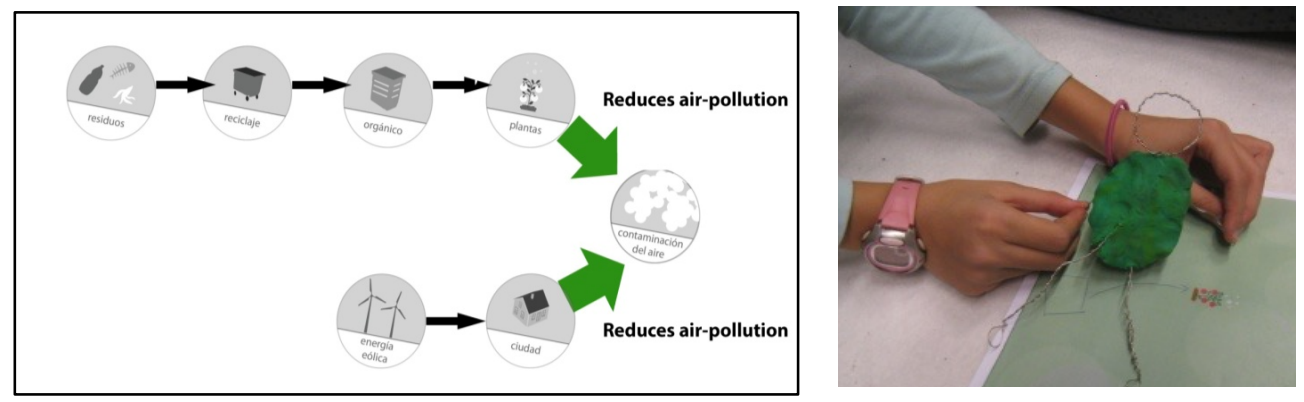

Figure 5: Left: A diagram depicting the reciprocal relationships between the different elements. Right: A student representing the relationship between plants and compost with the flexible anthropomorphic puppet. 


\subsection{Prototyping the embodied experience}

\subsubsection{What does this design stage involve?}

The goal of this design stage is to enable the co-designers to simulate a functional prototype of the interactive experience. Therefore, the design team needs to be provided with techniques including low-tech and mid-tech prototyping materials that can be easily manipulated. Furthermore, these techniques should allow redefining design ideas and test simulations of the real-time mechanics of the interactive experience. Prototyping is a common practice in co-design (Lim et al., 2008). Many participatory approaches are used for understanding user needs and for exploring design ideas (Druin, 1999; Muller and Druin, 2010) that have been brainstormed and elaborated in previous design stages. In the field of $\mathrm{HCl}$, software engineering and design prototypes often have been considered tools for evaluating design failures or success. Hence, prototypes are used not for providing concrete solutions but for discovering problems and for exploring design alternatives. In this context, Lim et al. (2008) highlighted that one primary strength of a prototype is its incompleteness, which makes it possible to focus on and investigate specific qualities without building a copy of the final design. The same authors argued that the nature of the prototype works as a "filter" that allows one to focus on particular aspects within an imagined or possible design space. In their opinion, the best prototype is one that makes the possibilities and limitations of a design visible and measurable.

\subsubsection{Why is this design stage important?}

In Full-Body Interaction, we are confronted with two additional challenges. In the design for FUBILEs, co-designers face difficulties when having to imagine aspects on a human scale rather than on a screen. These aspects involve dealing with ideas related to the design of large-scale interactive spaces, body enactment and gesticulation, merging physical and virtual space, etc. Thus, the prototyping techniques employed in this field must allow specifically exploring these design features. On the other hand, most prototyping tools are developed for screen-based interaction (e.g. software for wireframing such as Sketch, Balsamiq or Mockingbot). Thus, designers in the field of Full-Body Interaction need to invent and explore approaches that enable them to create adequate prototypes (Höysniemi et al., 2005; Landry et al., 2012).

\subsubsection{How has this design stage been employed in practice?}

In this design stage, we propose using prototype techniques that (1) can be easily manipulated and test simulations of the real-time mechanics of the interactive experience; (2) allow designers to explore body actions on a human scale, and (3) filter specific qualities of the prototype to discover problems and for exploring design alternatives. In our research, we explored the benefits of the Wizard of Oz prototyping (Markopoulos et al., 2008) Technique within the EcoSystem project. As previously mentioned, the goal of this interactive experience was to improve children's global understanding of environmental issues related to air-pollution. The children were invited to experiment with the existing relationships between $\mathrm{CO}_{2}$ emission and strategies for its reduction and absorption. They had to coordinate their physical actions between three game roles: (1) planting vegetables to produce oxygen, (2) producing wind energy to reduce the $\mathrm{CO}_{2}$ emissions of a steam power station, and (3) recycling waste from the city to avoid incineration. The prototype was based on a floor projection representing a virtual simulation of a semi-urban ecosystem and created with lowand high-fidelity materials. Some game mechanics were partially implemented in the 
programming language Processing. For instance, each time a child "grew a vegetable" by interacting with the floor in a specific location, the design expert who was manipulating the mechanics of the projection created a virtual tomato in the same place. The design expert also controlled the velocity of the windmills according to the children's physical actions. The other part of the interactive experience was directly manipulated using physical objects. For instance, to simulate pollution, we used cotton balls that one designer manipulated in realtime on a computer screen (Figure 6, picture 1). These actions were recorded by a camera that was connected to a video projector (Figure 6, picture 2). The final image was projected on the floor (Figure 6, picture 4). The recycling task consisted of sorting physical paper sheets with different kinds of waste that was spread out over the game floor (Figure 7 , picture 3).

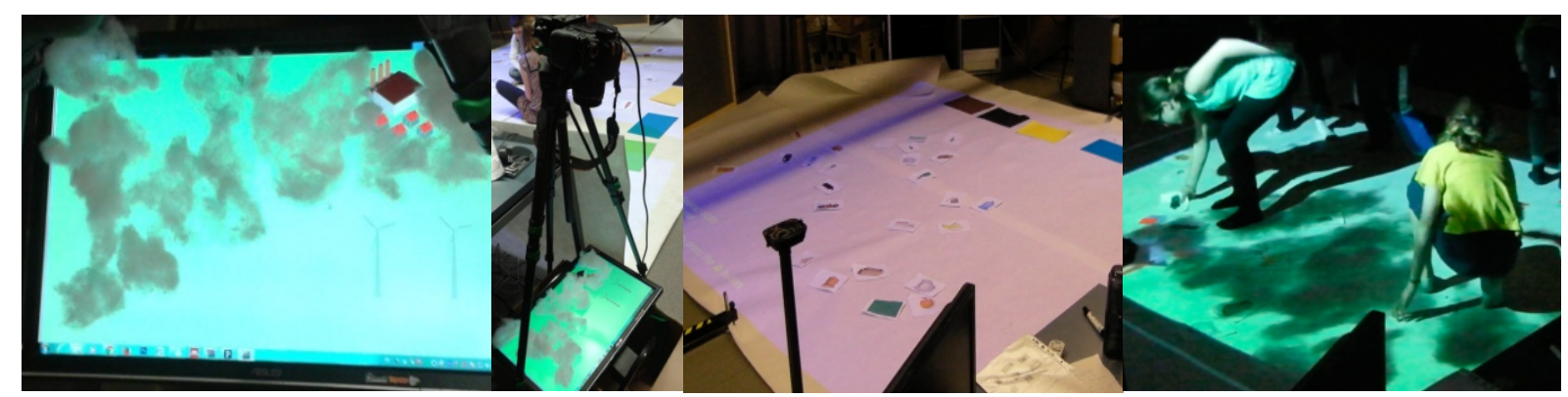

Figure 06: Left: Mixed-fidelity approach using Wizard of Oz prototyping. A camera recorded the prototype during the manipulation process. Centre: The camera was connected to a projector projecting the final image on the floor. Right: Paper sheets with different kinds of waste were spread out over the playground (picture right).

We explored the prototype with ten children (girls $=5$; boys $=5$ ) aged between 11 and 12 years from a local school. They were randomly divided into three groups of three to four members. One group at a time was taken to the laboratory where the FUBILE was set up. To ground their expectations, we informed them that we would use a mid-fidelity prototype (Hanna et al., 1997) and explained that they were invited to take part in improving the game. Using role cards (Figure 8), we introduced the common goal and the three different interaction roles (wind power, plants, and recycling). The cards were designed in collaboration with field experts in environmental education and provided key information about the elements in the environment and their reciprocal relations. They were read aloud by one child at a time and the children were invited to play for 6 minutes. They were encouraged to alternate the game roles during the playing time. The purpose of the study was to observe children's intuitive actions with the prototype and if user-generated meanings on the physical action they performed helped to enhance better proposed learning goals. Therefore, the children did not receive any explicit instructions on the physical action that they had to perform and had to invent and improvise. The session was video-recorded and analysed following our multimodal methodological approach (see Section 3.6.3).

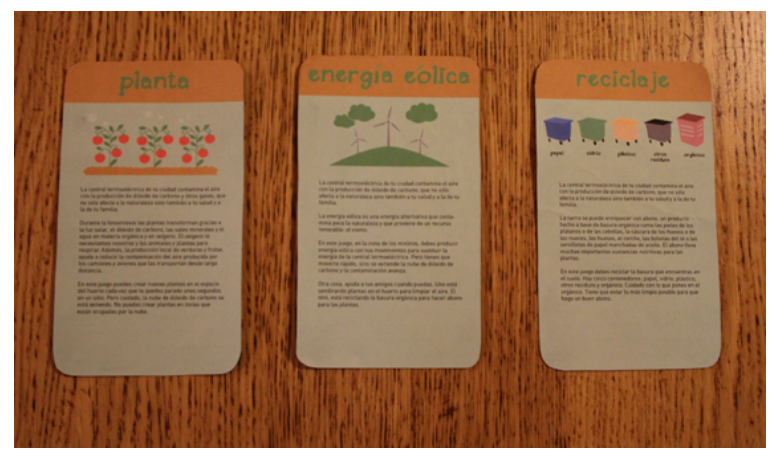


The Wizard of Oz prototyping Technique allowed us to understand how children intuitively interacted without the influence of external mediation or requests. For example, our observations confirmed that the children seemed to have a preference for iconic gestures (Anastopoulou et al., 2011; Markopoulos et al., 2008). We observed that several children intuitively tried to spin or move their arms to activate the windmill. For the recycling role, they enacted collecting waste and throwing it in the correct container. The plant growing action consisted of touching or rubbing the floor projection as if the children were sowing the seed. Furthermore, it allowed us to observe the potential of the spatial configuration of the largescale environment, i.e., which sensorimotor experience the interface of virtual environment evoked. The physical materials that we used permitted us and the children to easily manipulate the game elements in real-time according to the game mechanics.

Building on our experiences in this project, we recommend employing prototyping techniques in Full-Body Interaction that foster a critical analysis of the design ideas on a real human scale. We conclude that this design technique is particularly useful to confirm and refine initial ideas for physical actions by comparing the co-designers' proposals with children's intuitive interaction in an existing prototype.

\subsubsection{Which risks and limitations does this technique involve?}

We observed that many children focused on discussing with their peers how to solve the task rather than performing the movement. On the other hand, the fact that they were playing in a group and alternating the roles evoked a high tendency to imitate others who had previously performed physical actions. Another explanation for the scarcity of the children's design proposals can be partially found in the failure to provide them with the opportunity to complement their interaction ideas with explicit verbal explanations. Therefore, it was difficult to grasp the children's reasons and connotations behind certain design choices. To refine this technique, we propose generating children time for group discussions and self-reflection. One way could be to involve the children already in the process of creating the prototype. This procedure would give them the opportunity, together with the rest of the co-design team, to explore different alternatives for the design and allow them to bodystorm the initial proposals for physical actions with low-fidelity materials. Another solution could be to allow the children to experience the FUBILE several times and provide breaks in between for ideation in exchange with their peers. Another approach may be to constantly capture children's ideas on different levels of perception such as through using methods which elicit children's verbal contributions during the experience (e.g., the Think Aloud Method (Zaman, 2007)).

\subsection{Understanding the embodied experience with the prototype}

\subsubsection{What does this design stage involve?}

The goal of this design stage is to understand how children create bridges between the embodied experience and knowledge construction while interacting with a functional FUBILE. Therefore, we propose to provide the co-design team with a set of techniques to research how children build their understandings from an embodied experience during and after children's interaction with the functional prototype. The co-design team needs to focus, on the one hand, on researching meaning-making during the experience, i.e. how children's 
"sensing-in-action can lead them to make sense of action" (Malinverni et al., 2016a). On the other hand, in this design stage is also important to verify if the physical actions that were implemented in the prototype are natural and intuitive for the children.

\subsubsection{Why is this design stage important?}

The comprehension of the interactive experience from children's perspective is the basis for the evaluation and refinement of the prototype. It allows co-designers to put themselves in the place of the children, understand their worldviews and reasons for certain behaviours during the experience. Considering children's perspectives on worldviews that are related to their way of playing and certain educational contexts also increases their motivation for the engagement with the embodied experience.

\subsubsection{How has this design stage employed in practice?}

In this design stage, we propose using research methods and elicitation techniques that allow (1) co-designers to understand children's worldviews, and (2) triangulating the outcomes using different techniques to confirm co-designers' interpretations of children's behaviours with a prototype. For understanding embodied meaning-making in FUBILEs we employed a Multimodal methodological approach to analyse children's in situ interaction with the project Archimedes (Malinverni et al., 2016a), a FUBILE based on the Interactive Slide platform (Soler-Adillon, 2009). The Interactive Slide is an exergame platform based on a large inflatable slide augmented with digital technology (Figure 9). Four main parts compose the interface: a sliding surface where the digital content is projected, an upper part where the children can stand before sliding down, a bottom part where the children land after sliding, and the lateral stairs. The Interactive Slide allows a natural and playful interaction as children interact with the digital content by moving through and across the sliding surface, where the interactive content is projected.

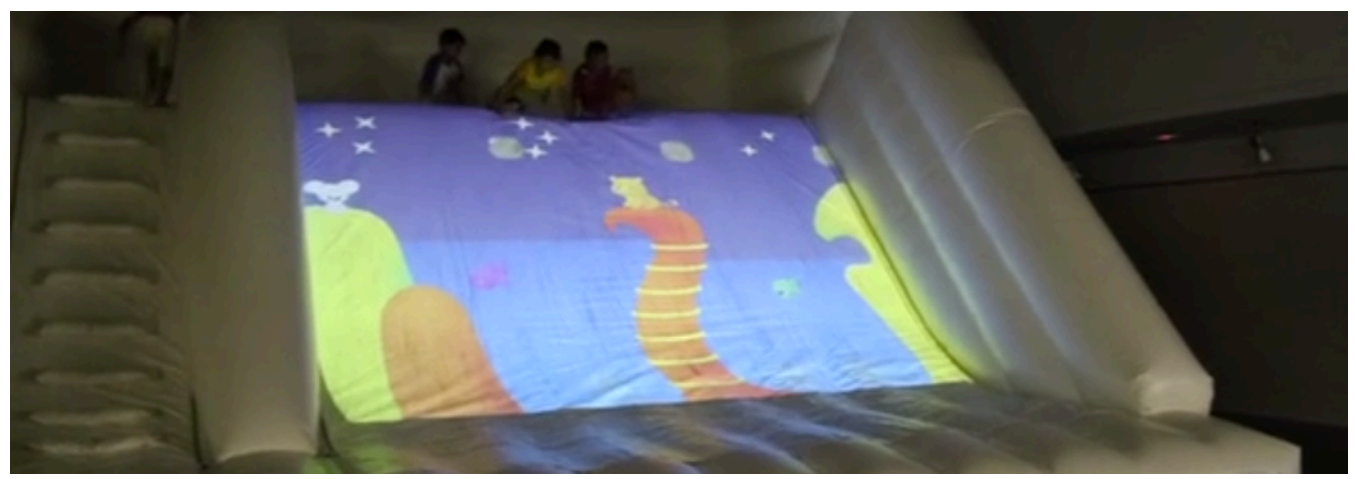

Figure. 09: The FUBILE Archimedes using the Interactive Slide.

The game Archimedes was originally designed to support children's hands-on learning on the notion of buoyancy and Archimedes' principle (Malinverni et al., 2012). The goals of the game are: 1) to allow the cat to cross a pool of water by building a bridge; 2) to raise the water level in the right pool to allow the green fish to jump to the left pool and meet its pink fish friend. To accomplish these goals, the children have to employ a set of objects that scroll horizontally along the upper part of the game and understand the physical properties of the objects and make a strategic use of them, since their number is limited. To interact with the game, the children must slide over one of the objects and drag it down into one of the pools. 
One main goal of this study was to illustrate different possible paths through which children create bridges between embodied experience and the construction of meaning. For the study, a total of 48 children (mean age: 11) were recruited from a local school to participate. A week before the study, we administered a short open-ended questionnaire on the school premises to evaluate the children's previous knowledge on Archimedes' principle and buoyancy. The study itself was carried out at our university during two mornings. Upon their arrival, the children were divided into groups of four. Thus, a total of 12 groups of four children played with the game. Then, one group at a time was taken to the room where the Interactive Slide was set-up. The children were introduced to the game through a short video tutorial that explained the main goals and rules of the game. After that, the children were invited to play with the game over the course of a six-minute session. Subsequently, the children were asked to fill out a short questionnaire about their user experience and then they were individually interviewed by a design expert following a semi-structured format. The questions were related to their understanding of the game and to the physical properties of the objects of the game.

The children's activity during the game and interviews was video-recorded. For the analysis, we employed our multimodal methodological approach as follows. A design expert reviewed the overall video materials of children playing and performed a narrative transcription of the 12 videos by focusing on overall group behaviour. Then, two design experts discussed the results and four case studies were identified. Each case study was selected as being representative of one of the observed paths that the children used to create bridges between embodied experience and meaning construction. One of the design experts then performed an in-depth multimodal transcription by focusing on the behaviour of each child, during the game and during the interview. These transcriptions were performed by annotating both data proceeding from verbal interaction as well as from embodied resources (the child's position and sensorimotor exploration). Finally, results were further discussed and elaborated by the two design experts.

The results of the study showed that the children adopted different ways to understand the embodied experience such as: the social construction of meaning, the action-perception loop, the adoption of different perspectives, and the use of previous knowledge. For instance, one child showed a certain spatial and temporal separation between her sensorimotor experience and the way she constructed meaning. Her activity on the Interactive Slide mainly focused on exploring variations in "sliding down" without paying much attention to the game, although she was taking an observer position to construct knowledge about the functions of the system. In this process, she observed the actions of her peers and she shifted her role to transform the embodied experience into an 'object-to-think-with'. Meanwhile, two other children constructed their meanings by creating a loop between action and observation. In both cases, their understanding started to emerge when they changed their movement patterns. While at the beginning both mostly focused on the action of sliding, when they started to turn around and take time to observe the effects of their actions on the sliding surface, they both engaged in a more strategic approach to the "learning aspect" of the game. Nonetheless, while the first girl assumed a systematic trial and error approach, the second child all of a sudden fathomed specific insight onto the game by recalling previous knowledge. Both cases point out the role of the action-perception loop in mediating between embodied experiences and meaning-making. Nonetheless, in this relation, different strategies may be employed, suggesting the importance of self-regulating the pace of the experience to build one's own understanding. Consequently, by fully acknowledging and taking into account embodiment, Multimodal Analysis constituted an appropriate and 
consistent research method to better understand meaning construction and learning in these kinds of environments. At the same time, it provided relevant insights to guide Design-Based research processes and define design improvements.

Building on our experiences in this project, we recommend employing techniques that are adapted to children's skills and motivate them to express their experience with the prototype. Multimodal Analysis in combination with the triangulation of other assessment techniques such as open-ended questionnaires or individual interviews allowed us to better understand children's ways of engaging with the experience in situ, experimenting with it and transforming it into an object of knowledge.

\subsubsection{Which risks and limitations does this technique involve?}

One shortcoming was that only the design experts had been involved in the interpretation of the data that resulted from the research method without verifying them again with the users of the interactive experience. Consequently, this procedure unbalanced the power and decision making within the design team because the design experts decided what mattered for the experience and selected the relevant results for design refinements. Another issue is the general difficulty of transforming the results from Multimodal Analysis into actionable knowledge for guiding the design refinements to communicate them to the rest of the design team. Future work needs to explore accessible and inspirational formats to report the results resulting from Multimodal Analysis to the entire co-design team.

\section{Discussion}

In this article, we have presented the different design stages of the FUBImethod. It aimed at leveraging children's participation in a co-design team and capacitating co-designers to develop FUBILEs that are adequate and consistent with the specificities of embodied interaction. The method provides means to benefit from children's expertise in Full-Body movement and natural playfulness. Furthermore, it offers step-wise guidelines for using research methods to guide an iterative process for making adequate design choices and refinements.

To illustrate the specific qualities of the design stages of the FUBImethod and the benefits for researchers, designers and practitioners in this field, we used the FACIT (Framework for Analysis and Creation of Intergenerational Techniques) classification method PD approach (Walsh et al., 2013). This framework aims to guide the description of co-design techniques and provides specific values that are relevant to co-design teams. Specifically, the framework focuses on three main aspects: the design partners, the design goal, and the design technique. We used the FACIT framework as follows. First, we structured the properties of the FUBImethod according to the dimensions of this framework. The dimensions (1) design space and (2) maturity of design refer to the design goals of each design stage, while (3) portability and (4) physical interaction concern qualities related to the design stage itself. For our description, we added one more dimension related to the (5) material required during each design stage (e.g. low- and high tech materials, the fidelity of technology used). Second, we used two of the dimensions (6) partner experience and (7) need for accommodation to describe the relationship between the techniques used during the design stage and co-designers. Building on this framework, we will now highlight the specific properties and advantages of each design stage (Table 1) and reflect upon children's experience as co-designers using the FUBImethod (Table 2). In our discussion, we will focus 
specifically on two main aspects: (1) How is the FUBImethod different to other approaches in the $\mathrm{HCl}$ community?; and (2) Which expertise do children provide during these design processes and how could their participation be strengthened?

\subsection{Benefits of the FUBImethod}

The first two design stages, defining a common ground and defining goal and context appropriateness, are essential for the co-design process and form the basis of the design project. The research methods employed can be generalized to other application areas in $\mathrm{HCl}$, such as computer-based, application design or tangible technologies. They require the use of traditional low-tech material for group activities (e.g., white boards, pen and paper, post-it notes, etc.). Most of the techniques proposed do not require any specific locations for their employment. However, we also propose techniques for the second design stage that aim to stimulate context awareness and, therefore, should be conducted in locations related to the design context. For instance, the Dwelling Space Technique is based on an interview activity in a site-specific location to gain insights into aspects that children find interesting and engaging in the environment. The technique allows co-designers to understand children's worldviews, interpretations, cultural values and preferences towards the proposed context. The technique also helps us to analyse if Full-Body Interaction as a medium could add additional value to the educational experience.

The next two design stages, awakening embodied awareness and translating embodied experience, are specific for the design of embodied interaction. In both design stages, we propose techniques based on bodystorming, performance, and gesture-elicitation to stimulate sensations related to proprioception, space awareness, and proxemics. The goal of these design stages is to train the design team in using their felt-experience to define features for Full-Body Interaction design proposals. Thus, the main "material" used in these design stages are one's own body. The techniques used can be conducted in general workshop rooms or specific locations that are connected to the design context. The aim is to direct co-designers' attention to relevant sensorimotor and spatial qualities that need to be taken into account for the design and inspire design ideas.

The last two design stages, prototyping the embodied experience and evaluating the embodied experience, can again be generalized to other application areas working with children. Nevertheless, they also address specific challenges in Full-Body Interaction such as prototyping and evaluation of user interaction in large-scale environments. Furthermore, our focus on Multimodal Analysis to research user contributions embraces the very nature of embodiment. The prototyping techniques proposed require bodily activity of the tester and the use of low- and high-tech material to simulate interaction and real-time mechanics of the FUBILE. To draw suitable conclusions for design refinements, the prototypes should be explored in locations simulating the real-world environment or directly in situ.

The last three design stages form part of the iterative design process and assessment cycle of the FUBImethod, i.e., by considering design and assessment as inseparable instances, mutually reinforcing and informing each other, this structure allows us to constantly evaluate the suitability and feasibility of the design ideas in accordance with children's felt-experience and worldviews (Malinverni et al., 2016c). For instance, detecting aspects that do not convey the desired design goals requires the design partners to return to previous design stages, such as prototyping and bodystorming, to refine the final embodied experience. 
Table 1. Overview of the properties of the FUBImethod

\begin{tabular}{|c|c|c|c|c|c|c|}
\hline 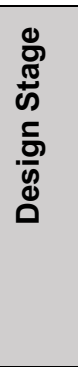 & $\begin{array}{l}\text { Maturity of } \\
\text { Design } \\
\text { For which } \\
\text { design } \\
\text { stage are } \\
\text { the research } \\
\text { methods } \\
\text { used } \\
\text { suitable? }\end{array}$ & \multicolumn{2}{|c|}{$\begin{array}{l}\text { Which design techniques and } \\
\text { research method are required? }\end{array}$} & $\begin{array}{l}\text { Required } \\
\text { Materials } \\
\text { What kind of } \\
\text { materials are } \\
\text { required for the } \\
\text { techniques } \\
\text { used? (low-tech, } \\
\text { high-tech, } \\
\text { technologies) }\end{array}$ & $\begin{array}{l}\text { Physical } \\
\text { Interaction } \\
\text { What kind of } \\
\text { materials are } \\
\text { required for the } \\
\text { techniques } \\
\text { used? (low- } \\
\text { tech, high-tech, } \\
\text { technologies) }\end{array}$ & $\begin{array}{l}\text { To which degree } \\
\text { does the research } \\
\text { method need to be } \\
\text { employed in } \\
\text { a specific location? }\end{array}$ \\
\hline & & Elicitation & Analysis & & & \\
\hline 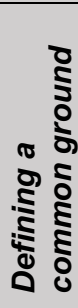 & $\begin{array}{l}\text { Foundation } \\
\text { of a co- } \\
\text { design } \\
\text { process }\end{array}$ & $\begin{array}{l}\text { Interviews, } \\
\text { open-ended } \\
\text { questionnaires, } \\
\text { group } \\
\text { discussions }\end{array}$ & $\begin{array}{l}\text { Critical } \\
\text { Discourse } \\
\text { Analysis }\end{array}$ & $\begin{array}{l}\text { Low-tech } \\
\text { materials (white } \\
\text { boards, pen and } \\
\text { paper, post-it } \\
\text { notes, etc.) }\end{array}$ & $\begin{array}{l}\text { Group } \\
\text { discussions } \\
\text { can take place } \\
\text { in workshop } \\
\text { rooms e.g., } \\
\text { with moveable } \\
\text { tables }\end{array}$ & $\begin{array}{l}\text { No specific } \\
\text { location required }\end{array}$ \\
\hline 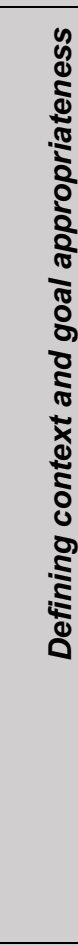 & $\begin{array}{l}\text { Early design } \\
\text { stage }\end{array}$ & $\begin{array}{l}\text { Assessment } \\
\text { tools for } \\
\text { conceptual } \\
\text { learning goals: } \\
\text { Open-ended } \\
\text { questionnaires, } \\
\text { interviews, } \\
\text { collages, } \\
\text { conceptual } \\
\text { maps } \\
\text { Elicitation } \\
\text { techniques: } \\
\text { collage, } \\
\text { drawings, } \\
\text { Pictionary } \\
\text { Technique } \\
\text { (Schaper et al., } \\
\text { 2014), Dwelling } \\
\text { Space } \\
\text { Technique, } \\
\text { Signifying } \\
\text { Space } \\
\text { Technique } \\
\text { (Schaper and } \\
\text { Pares, 2016) }\end{array}$ & $\begin{array}{l}\text { Multimodal } \\
\text { Analysis }\end{array}$ & $\begin{array}{l}\text { Low-tech } \\
\text { materials (white } \\
\text { boards, pen and } \\
\text { paper, post-it } \\
\text { notes, etc.); } \\
\text { high-tech } \\
\text { material (photo } \\
\text { and video } \\
\text { cameras, } \\
\text { printer, etc.) }\end{array}$ & $\begin{array}{l}\text { Traditional } \\
\text { assessment } \\
\text { tools take } \\
\text { place in } \\
\text { workshop } \\
\text { rooms e.g., } \\
\text { with moveable } \\
\text { tables; playful } \\
\text { activities such } \\
\text { as the Dwelling } \\
\text { Space and } \\
\text { Signifying } \\
\text { Space } \\
\text { techniques } \\
\text { require } \\
\text { physical } \\
\text { movement } \\
\text { around a } \\
\text { specific } \\
\text { location }\end{array}$ & $\begin{array}{l}\text { Traditional } \\
\text { assessment tools } \\
\text { and reflective } \\
\text { activities do not } \\
\text { require any } \\
\text { specific locations; } \\
\text { other playful } \\
\text { techniques such } \\
\text { as Dwelling } \\
\text { Space and } \\
\text { Signifying Space } \\
\text { should be used in } \\
\text { locations related } \\
\text { to the design } \\
\text { context }\end{array}$ \\
\hline 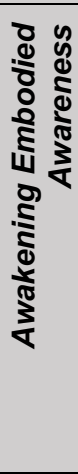 & $\begin{array}{l}\text { Early design } \\
\text { stage }\end{array}$ & $\begin{array}{l}\text { Bodystorming, } \\
\text { somatic } \\
\text { practices } \\
\text { (e.g., } \\
\text { Feldenkrais), } \\
\text { dance } \\
\text { performance, } \\
\text { theatre } \\
\text { exercises (e.g., } \\
\text { Situated } \\
\text { Performance, } \\
\text { Body Shadows } \\
\text { techniques) }\end{array}$ & $\begin{array}{l}\text { Multimodal } \\
\text { Analysis }\end{array}$ & $\begin{array}{l}\text { Low-tech } \\
\text { material can be } \\
\text { used as props } \\
\text { to stimulate } \\
\text { body sensations } \\
\text { related to felt- } \\
\text { experience, } \\
\text { space and } \\
\text { proxemics }\end{array}$ & $\begin{array}{l}\text { Require active } \\
\text { body } \\
\text { movement of } \\
\text { the } \\
\text { practitioners }\end{array}$ & $\begin{array}{l}\text { Techniques can } \\
\text { be employed in } \\
\text { locations related } \\
\text { to the design } \\
\text { context or } \\
\text { decontextualized } \\
\text { depending on the } \\
\text { focus of each } \\
\text { technique }\end{array}$ \\
\hline
\end{tabular}




\begin{tabular}{|c|c|c|c|c|c|c|}
\hline 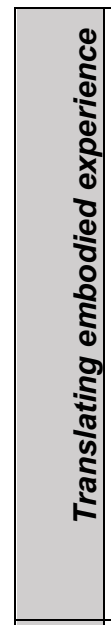 & $\begin{array}{l}\text { Iterative } \\
\text { design } \\
\text { stage }\end{array}$ & $\begin{array}{l}\text { Interaction } \\
\text { design ideation } \\
\text { techniques and } \\
\text { gesture } \\
\text { elicitation: } \\
\text { Bodystorming, } \\
\text { Puppet-Based } \\
\text { Design, Group } \\
\text { Environment, } \\
\text { Body Shadows }\end{array}$ & $\begin{array}{l}\text { Multimodal } \\
\text { Analysis; } \\
\text { Reflective } \\
\text { tools to make } \\
\text { design } \\
\text { choices e.g., } \\
\text { conceptual } \\
\text { Posters } \\
\text { (Halskov and } \\
\text { Dalsgaard, } \\
\text { 2007), } \\
\text { Reflective } \\
\text { Design } \\
\text { Document } \\
\text { (Halskov and } \\
\text { Dalsgaard, } \\
\text { 2012) } \\
\end{array}$ & $\begin{array}{l}\text { Own body, low- } \\
\text { tech materials } \\
\text { such as props } \\
\text { for } \\
\text { bodystorming } \\
\text { and role-play, } \\
\text { construction of } \\
\text { small-scale } \\
\text { prototypes and } \\
\text { puppets }\end{array}$ & $\begin{array}{l}\text { Require active } \\
\text { body } \\
\text { movement of } \\
\text { the } \\
\text { practitioners }\end{array}$ & $\begin{array}{l}\text { For inspirational } \\
\text { purposes, we } \\
\text { recommend } \\
\text { conducting the } \\
\text { activities in } \\
\text { locations related } \\
\text { to the design } \\
\text { context }\end{array}$ \\
\hline 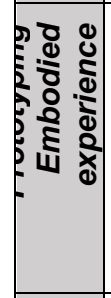 & $\begin{array}{l}\text { Iterative } \\
\text { design } \\
\text { stage }\end{array}$ & $\begin{array}{l}\text { Paper } \\
\text { prototyping, } \\
\text { small-scale } \\
\text { prototyping, } \\
\text { Wizard of Oz } \\
\text { prototyping }\end{array}$ & $\begin{array}{l}\text { Multimodal } \\
\text { Analysis }\end{array}$ & $\begin{array}{l}\text { Low- and mid- } \\
\text { tech material to } \\
\text { build a } \\
\text { functional } \\
\text { prototype }\end{array}$ & $\begin{array}{l}\text { Require active } \\
\text { movements to } \\
\text { manipulate } \\
\text { material and } \\
\text { bodystorm } \\
\text { design ideas }\end{array}$ & $\begin{array}{l}\text { For inspirational } \\
\text { purposes, we } \\
\text { recommend } \\
\text { conducting the } \\
\text { activities in } \\
\text { locations related } \\
\text { to the design } \\
\text { context }\end{array}$ \\
\hline 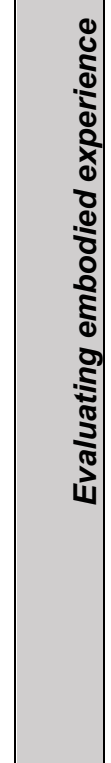 & $\begin{array}{l}\text { Iterative } \\
\text { design } \\
\text { stage }\end{array}$ & $\begin{array}{l}\text { Elicitation } \\
\text { techniques: } \\
\text { Reflective } \\
\text { Drawing, } \\
\text { collage, } \\
\text { Assessment } \\
\text { tools: } \\
\text { semi-structured } \\
\text { interviews and } \\
\text { questionnaire, } \\
\text { Affective Slider } \\
\text { (Betella et al., } \\
\text { 2013), Self- } \\
\text { Assessment } \\
\text { Manikin } \\
\text { (Bradley and } \\
\text { Lang, 1994), } \\
\text { Smilyeometer } \\
\text { (J. Read et al., } \\
\text { 2002), }\end{array}$ & $\begin{array}{l}\text { Multimodal } \\
\text { Analysis; } \\
\text { Content } \\
\text { Analysis }\end{array}$ & $\begin{array}{l}\text { Mid-tech } \\
\text { material to build } \\
\text { a functional } \\
\text { prototype }\end{array}$ & $\begin{array}{l}\text { Require active } \\
\text { movement to } \\
\text { explore the } \\
\text { prototype }\end{array}$ & $\begin{array}{l}\text { The evaluation } \\
\text { needs to take } \\
\text { place in the } \\
\text { location in which } \\
\text { the final } \\
\text { experience will be } \\
\text { employed }\end{array}$ \\
\hline
\end{tabular}

\subsection{Child partner experience}

Co-design is a polyvoiced perspective embracing complex and often blurred constellations of users, contexts, and purposes (Halskov and Hansen 2015). Specifically, when working with children, equal partnerships are difficult to manage because adults tend to set agendas, choose research projects and organize the design activities (Yip et al., 2017). The FUBImethod claims to involve children as partners in the design of FUBILEs by focusing on their expertise in felt-experience and their capabilities in playfulness. Therefore, we explored several embodied design techniques that specifically focus on child users. Thus, most of them are highly intuitive for children but still require an adult to set up the activity and conduct the sessions. We argue that the co-design team should give more credit to children's specific expertise in felt-experience and explore novel strategies on how they can teach this knowledge also to adults and collaboratively elaborate the procedure for design sessions. 
Table 27. Overview of the aspects related to the experience of the co-designers using the FUBImethod and possible application of design spaces.

\begin{tabular}{|c|c|c|c|}
\hline 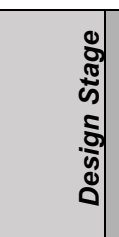 & $\begin{array}{l}\text { Partner Experience } \\
\text { Who provides the expertise? }\end{array}$ & $\begin{array}{l}\text { Need for accommodation } \\
\text { To which degree do the } \\
\text { research methods need to be } \\
\text { adapted to designers' skills and } \\
\text { cognitive ability? }\end{array}$ & $\begin{array}{l}\text { Design Space } \\
\text { How specific is the design } \\
\text { problem and technology } \\
\text { approach defined? }\end{array}$ \\
\hline 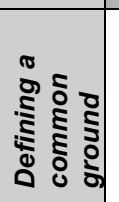 & Design Expert (analysis) & $\begin{array}{l}\text { Need for accommodation of the } \\
\text { reflective group activities by a } \\
\text { trained facilitator; need for } \\
\text { playful techniques to involve } \\
\text { children in the discussion }\end{array}$ & $\begin{array}{l}\text { Can be generalized to a wide } \\
\text { range of design spaces }\end{array}$ \\
\hline 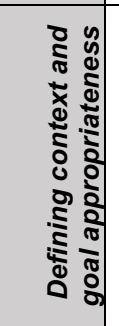 & $\begin{array}{l}\text { Design Experts and Field } \\
\text { Experts (design goals) } \\
\text { Design Expert (assessment), } \\
\text { Children (worldviews) }\end{array}$ & $\begin{array}{l}\text { Need for accommodation of the } \\
\text { reflective group activities by a } \\
\text { trained facilitator; need for } \\
\text { playful techniques to be } \\
\text { adapted to children skills and } \\
\text { capabilities }\end{array}$ & $\begin{array}{l}\text { Can be generalized to a wide } \\
\text { range of design spaces }\end{array}$ \\
\hline 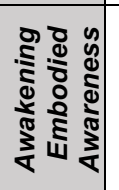 & $\begin{array}{l}\text { Field experts in somatic and } \\
\text { theatre practices (facilitation } \\
\text { techniques), Children (felt- } \\
\text { experience) }\end{array}$ & $\begin{array}{l}\text { Need for accommodation of } \\
\text { bodily-based exercises by a } \\
\text { professional or previous training } \\
\text { in those techniques }\end{array}$ & $\begin{array}{l}\text { Specific for experiences based } \\
\text { on embodied interaction }\end{array}$ \\
\hline 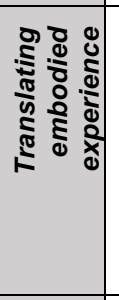 & $\begin{array}{l}\text { Design experts(facilitation } \\
\text { techniques), } \\
\text { Field Experts in somatic } \\
\text { practices (facilitation } \\
\text { techniques), } \\
\text { Children (felt-experience) }\end{array}$ & $\begin{array}{l}\text { The techniques used are highly } \\
\text { intuitive and do not have a need } \\
\text { for accommodation, however, } \\
\text { they do need to be adapted to } \\
\text { the age and capacity of the } \\
\text { designer, i.e., Puppet-Based } \\
\text { Design may not be adequate for } \\
\text { adults. }\end{array}$ & $\begin{array}{l}\text { Specific for experiences based } \\
\text { on embodied interaction }\end{array}$ \\
\hline 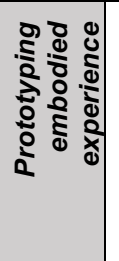 & $\begin{array}{l}\text { Design experts (facilitation } \\
\text { techniques), Children (felt- } \\
\text { experience, worldviews) }\end{array}$ & $\begin{array}{l}\text { Low-fidelity prototypes do not } \\
\text { have a need for } \\
\text { accommodation. Mixed-fidelity } \\
\text { approach may require } \\
\text { accommodation due to the } \\
\text { involvement of technical } \\
\text { solutions }\end{array}$ & $\begin{array}{l}\text { Can be generalized to a wide } \\
\text { range of design spaces }\end{array}$ \\
\hline 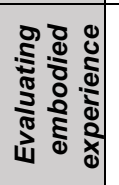 & $\begin{array}{l}\text { Design experts(assessment } \\
\text { tools and analysis), Children } \\
\text { (felt-experience, worldviews, } \\
\text { etc.) }\end{array}$ & $\begin{array}{l}\text { Need for accommodation for the } \\
\text { evaluation of the results }\end{array}$ & $\begin{array}{l}\text { Can be generalized to a wide } \\
\text { range of design spaces }\end{array}$ \\
\hline
\end{tabular}

\subsection{Limitations and Future Work}

In the projects presented in this study, one main drawback of the FUBImethod is that the design experts often only observed and evaluated children's contributions. As a consequence, the adults did not take part actively in the felt-experience activities nor the children in the evaluation of the design. One reason for this shortcoming is that the proposed techniques (e.g., Puppet-Based Design Technique) were adapted to children's skills and 
capabilities, i.e., an adult may use them in a different way that does not reveal any insights about children's felt-experience or even adults may reject their use because puppet play is a childish activity. On the other hand, the outcomes (written contributions, drawings, videorecordings, etc.) are formats that were difficult to simplify for participatory evaluation with the children. Novel approaches need to attempt to integrate both intergenerational design techniques (Walsh et al., 2013) and participatory evaluation methods (Moser, 2012; Spiel et al., 2017) in this framework.

In addition, our analysis depicted that there is still a lack of research methods that focus on the reflective practice of design ideas and the communication of intermediate-level knowledge (Barendregt et al., 2017) between design stages. This shortcoming suggests that design experts tend to have a stronger role in refining designs and taking final decisions. In future work, co-designers need to explore and develop new strategies to translate design outcomes of ideation and evaluation sessions into workable formats for reflective tools.

Furthermore, inspired by current research in embodied elicitation techniques (Wilde et al., 2017), we are currently exploring the benefits of including physical objects as props in design stages that involve bodystorming techniques (Stage 3: Awakening Embodied Awareness and Stage 4: Translating Embodied Experience). We argue that the inclusion of physical objects may be beneficial to complement these techniques to help co-designers better understand the relation between the propioception, space, and proxemics. We have initiated attempts to design a kit based on these features, namely the FUBlkit.

Finally, we explored the FUBImethod in the context of a complex research project consisting of several subprojects. Three of the subprojects presented run through an evaluation-driven design process, starting with a contextual inquiry study, co-design with multiple stakeholders and an iterative evaluation of the interactive experience. However, we used each context as a testbed to focus on a specific aspect of the method. First, in the subproject Refugi 307, we were interested in understanding and enhancing collaboration within a complex design team of design experts, field experts and children. On the other hand, the site-specific location provided us with a context to explore techniques that focused on children's interaction with a physical space and novel opportunities to enhance the educational experience of the guided visit through Full-Body Interaction. Second, the subproject Magical Movements, offered us the opportunity to work in the context of physical movement theatre and to elaborate embodied elicitation techniques with field experts. Third, the project EcoSystem allowed us to explore playful design techniques to translate children's ideas into workable prototypes. The fourth subproject, Archimedes, was first developed through a designer-driven approach (Malinverni et al., 2012). In the case study presented (Malinverni et al., 2016) we carried out a qualitative, idiographic study and took upon a different lens on understanding how children create bridges between embodied experience and meaning construction while interacting with a Full-Body Interaction Learning Environment. For these reasons, we have not been able to employ all design stages in a single project. We encourage other scholars in this research area to apply our method and explore the flexibility of our design stages.

\section{Conclusions}

The FUBlmethod proposed presents a novel strategy to engage children in co-design processes for Full-Body interactive experiences and focuses specifically on their expertise in the body that they can contribute to the design. The method is not exclusively an approach developed for the application in design projects related to non-formal education. Several 
design stages are essential for a successful collaboration between design partners in codesign processes, and research methods can be generalized to a wide range of design spaces, e.g., bodystorming for ideation and multimodal analysis to research user contributions communicated through different resources. Furthermore, we believe that other research fields can also benefit from focusing on design aspects which require children's skills and expertise. They are not only experts in play and worldviews for experiences designed for young users. Children may also provide insights into other contexts due to their playful way of approaching the world.

\section{Acknowledgements}

We thank all the schools that participated in the study and the Spanish Ministry of Economy and Competitiveness (Grant TIN2014-60599-P) for supporting the project (see also project webpage: https://www.upf.edu/web/evaluation-driven-design). We are particularly grateful for the support and inspiration provided by the theatre school Plàudite - Arts Escèniques de Pròximitat during this project.

\section{References}

Ackermann, E.K., 2004. Constructing Knowledge and Transforming the World, in: Tokoro, M., Steels, L. (Eds.), A Learning Zone of One's Own: Sharing Representations and Flow in Collaborative Learning Environments. IOS Press, Amsterdam, Netherlands, pp. 1537.

Alaoui, S.F., Bevilacqua, F., Jacquemin, C., 2015. Interactive Visuals as Metaphors for Dance Movement Qualities. ACM Trans. Interact. Intell. Syst. 5, 1-24. doi: $10.1145 / 2738219$

Alaoui, S.F., Caramiaux, B., Serrano, M., Drii, E./, Bevilacqua, F., 2012. Movement Qualities as Interaction Modality, in: Proceedings of the Designing Interactive Systems Conference Pages (DIS '12). ACM, New York, New York, USA, pp. 761-769. doi:10.1145/2317956.2318071

Alborzi, H., Hammer, J., Kruskal, A., Lal, A., Schwenn, T.P., Sumida, L., Wagner, R., Hendler, J., Druin, A., Montemayor, J., Platner, M., Porteous, J., Sherman, L., Boltman, A., Taxén, G., Best, J., 2000. Designing StoryRooms: Interactive Storytelling Spaces for Children, in: Proceedings of the Conference on Designing Interactive Systems Processes, Practices, Methods, and Techniques (DIS '00). ACM Press, New York, NY, USA, pp. 95-104. doi:10.1145/347642.347673

Anastopoulou, S., Sharples, M., Baber, C., 2011. An evaluation of multimodal interactions with technology while learning science concepts. Br. J. Educ. Technol. 42, 266-290. doi:10.1111/j.1467-8535.2009.01017.x

Antle, A.N., 2013. Research opportunities: Embodied child-computer interaction. Int. J. Child-Computer Interact. 1, 30-36. doi:10.1016/j.ijcci.2012.08.001

Antle, A.N., Corness, G., Droumeva, M., 2009. Human-computer-intuition? Exploring the cognitive basis for intuition in embodied interaction. Int. J. Arts Technol. 2, 235-254. doi:10.1504/IJART.2009.028927

Barendregt, W., Torgersson, O., Eriksson, E., Börjesson, P., 2017. Intermediate-Level Knowledge in Child-Computer Interaction: A Call for Action, in: Proceedings of the 2017 Conference on Interaction Design and Children - IDC '17. ACM, New York, NY, USA, pp. 7-16. doi:10.1145/3078072.3079719 
Barsalou, L.W., 2008. Grounded cognition. Annu. Rev. Psychol. 59, 617-645. doi:10.1146/annurev.psych.59.103006.093639

Bekker, M., Beusmans, J., Keyson, D., Lloyd, P., 2003. KidReporter: A user requirements gathering technique for designing with children. Interact. with Comput. 5438, 7-9. doi:10.1016/S0953-5438(03)00007-9

Betella, A., Inderbitzin, M., Bernardet, U., Verschure, P.F.M.J., 2013. Non-anthropomorphic expression of affective states through parametrized abstract motifs, in: Poster Sessions, Interactive and Artistic Events at the Afective Computing and Intelligent Interaction Conference. doi:10.1109/ACII.2013.78

Boal, A., 1992. Games for actors and non-actors. Routledge, London, UK.

Bradley, M., Lang, P.J., 1994. MEASURING EMOTION : THE SELF-ASSESSMENT SEMANTIC DIFFERENTIAL MANIKIN AND THE 25.

Brandt, E., Grunnet, C., 2000. Evoking the future: Drama and props in user centered design, in: Proceedings of Participatory Design Conference (PDC 2000). pp. 11-20.

Connell, S., Kuo, P., Liu, L., Piper, A.M., 2013. A Wizard-of-Oz Elicitation Study Examining Child-Defined Gestures With a Whole-Body Interface, in: Proceedings of the 12th International Conference on Interaction Design and Children. ACM, New York, NY, USA, pp. 277-280.

Corbin, J.M., Strauss, A., 1990. Grounded theory research: Procedures canons and evaluative criteria. Qual. Sociol. 13, 3-21.

Dindler, C., Iversen, O.S., 2014. Relational expertise in participatory design, in: Proceedings of the 13th Participatory Design Conference on Research Papers - PDC '14. ACM, New York, NY, USA, pp. 41-50. doi:10.1145/2661435.2661452

Dourish, P., 2001. Where the Action Is: The Foundations of Embodied Interaction. MIT press. doi:10.1162/leon.2003.36.5.412

Druin, A., 2002. The Role of Children in the Design of New Technology 21, 1-25.

Druin, A., 1999. Cooperative Inquiry: Developing New Technologies for Children with Children. Proc. SIGCHI Conf. Hum. Factors Comput. Syst. 14, 592-599.

Edwards, A., 2010. Being an Expert Professional Practitioner, Professional and Practicebased Learning. Springer Netherlands, Dordrecht. doi:10.1007/978-90-481-3969-9

Enyedy, N., Danish, J.A., Delacruz, G., Kumar, M. 2012., 2012. Learning physics through play in an augmented reality environment. Int. J. Comput. Collab. Learn. 7, 347-378.

Flynn, B., 2013. v-Embodiment for cultural heritage, in: Digital Heritage International Congress. IEEE, Marseille, France, pp. 347-354.

doi:10.1109/DigitalHeritage.2013.6743759

Françoise, J., Candau, Y., Alaoui, S., Schiphorst, T., 2017. Designing for Kinesthetic Awareness: Revealing User Experiences through Second-Person Inquiry, in: Proceedings of the $2017 \mathrm{CHI}$ Conference on Human Factors in Computing Systems. ACM, New York, NY, USA, pp. 5171-5183.

Frauenberger, C., Good, J., Fitzpatrick, G., Iversen, O.S., 2015. In pursuit of rigour and accountability in participatory design. Int. J. Hum. Comput. Stud. 74, 93-106. doi:10.1016/j.ijhcs.2014.09.004

Freiler, T.J., 2008. Learning Through the Body. New Dir. Adult Contin. Educ. 37-47. 
doi:10.1002/ace

Giaccardi, E., Paredes, P., Díaz, P., Alvarado, D., 2012. Embodied Narratives: A

Performative Co-Design Technique, in: In Proceedings of the Designing Interactive Systems Conference (DIS '12). ACM, New York, NY, USA, pp. 1-10.

Gibson, J.J., 2014. The theory of affordances (1979), in: The People, Place, and Space Reader. pp. 56-60. doi:10.4324/9781315816852

Glenberg, A.M., 2010. Embodiment as a unifying perspective for psychology. WIREs Cogn. Sci. 1, 586-596. doi:10.1002/wcs.55

Goldin-Meadow, S., 2011. Learning through gesture. Wiley Interdiscip. Rev. Cogn. Sci. 2, 595-607. doi:10.1002/wcs.132

Goldin-Meadow, S., Alibali, M., 2002. Looking at the hands through time: A microgenetic perspective on learning and instruction, in: Granott, N., Parziale, J. (Eds.), Microdevelopment: Transition Processes in Development and Learning. Cambridge University Press, Cambridge, England, pp. 80-106. doi:http://dx.doi.org/10.1017/CBO9780511489709.004

Grønbæk, K., Iversen, O.S., Kortbek, K.J., Nielsen, K.R., Aagaard, L., 2007. IGameFloor - A Platform for Co-Located Collaborative Games Kaj, in: Proceedings of the International Conference on Advances in Computer Entertainment Technology - ACE '07. ACM Press, New York, NY, USA, p. 64. doi:10.1145/1255047.1255061

Halskov, K., Dalsgaard, P., 2007. The emergence of ideas: the interplay between sources of inspiration and emerging design concepts. CoDesign 3, 185-211. doi:10.1080/15710880701607404

Hanna, L., Risden, K., Alexander, K.J., 1997. Guidelines for usability testing with children. Interactions 4, 9-14. doi:10.1145/264044.264045

Harrison, S., Sengers, P., Tatar, D., 2011. Making epistemological trouble: Third-paradigm $\mathrm{HCl}$ as successor science. Interact. Comput. 23, 385-392. doi:10.1016/j.intcom.2011.03.005

Hickey-Moody, A., Palmer, H., Sayers, E., 2016. Diffractive pedagogies: dancing across new materialist imaginaries. Gend. Educ. 28, 213-229. doi:10.1080/09540253.2016.1140723

Hoff, L., Hornecker, E., Bertel, S., 2016. Modifying Gesture Elicitation: Do Kinaesthetic Priming and Increased Production Reduce Legacy Bias?, in: Proceedings of the TEI '16: Tenth International Conference on Tangible, Embedded, and Embodied Interaction (TEI '16). ACM, New York, NY, USA, pp. 86-91.

Höök, K., 2010. Transferring qualities from horseback riding to design, in: Proceedings of the 6th Nordic Conference on Human-Computer Interaction Extending Boundaries NordiCHI '10. ACM, New York, NY, USA, pp. 226-235. doi:10.1145/1868914.1868943

Höök, K., Jonsson, M.P., Ståhl, A., Mercurio, J., 2016. Somaesthetic Appreciation Design, in: Proceedings of the $2016 \mathrm{CHI}$ Conference on Human Factors in Computing Systems. ACM, New York, NY, USA, pp. 3131-3142. doi:10.1145/2858036.2858583

Hornecker, E., Buur, J., 2006. Getting a grip on tangible interaction: a framework on physical space and social interaction., in: Proceedings of the SIGCHI Conference on Human Factors in Computing Systems. ACM, New York, NY, USA, pp. 437-446.

Hornecker, E., Honauer, M., Ciolfi, L., 2014. Technology Augmentation of Historic 
Cemeteries - A Cross Site Comparison, in: Online Proceedings of the 8th International Conference on Tangible, Embedded and Embodied Interaction (TEl'14).

Höysniemi, J., Hämälainen, P., Turkki, L., Rouvi, T., 2005. Children's intuitive gestures in vision-based action games. Commun. ACM 48, 44-50.

lacucci, G., lacucci, C., Kuutti, K., 2002. Imagining and experiencing in design, the role of performances, in: In Proceedings of the Second Nordic Conference on Human-

Computer Interaction - NordiCHI '02. ACM Press, New York, NY, USA, pp. 167-176. doi:10.1145/572021.572040

lacucci, G., Kuutti, K., Ranta, M., 2000. On the Move with a Magic Thing: Role Playing in Concept Design of Mobile Services and Devices, in: Proceedings of the 3rd Conference on Designing Interactive Systems: Processes, Practices, Methods, and Techniques. ACM, New York, NY, USA, pp. 193-202.

livari, N., Kinnula, M., Kuure, L., 2015. With best intentions: A Foucauldian examination on children's genuine participation in ICT design. Inf. Technol. People 28, 246-280. doi:10.1108/ITP-12-2013-0223

Iversen, O.S., Dindler, C., 2013. A Utopian agenda in child-computer interaction. Int. J. ChildComputer Interact. 1, 24-29. doi:10.1016/j.jjcci.2012.08.002

Iversen, O.S., Smith, R.C., Dindler, C., 2017. Child as Protagonist: Expanding the Role of Children in Participatory Design, in: Proceedings of the 2017 Conference on Interaction Design and Children - IDC '17. ACM, New York, NY, USA, pp. 27-37. doi:10.1145/3078072.3079725

Jakobsen, C., 2012. Dolls as props representing users in design: physical qualities and their application, in: Proceedings of the 24th Australian Computer-Human Interaction Conference. ACM, New York, NY, USA, pp. 263-272. doi:10.1145/2414536.2414581

James, A., Jenks, C., Prout, A., 1998. Theorizing Childhood. Polity Press, Cambridge.

Jewitt, C., 2013. Multimodal methods for researching digital technologies. SAGE Handb. Digit. Technol. Res. 250-265. doi:10.4135/9781446282229.n18

Jones, S.S., 2009. The development of imitation in infancy. Philos. Trans. R. Soc. B Biol. Sci. 364, 2325-2335. doi:10.1098/rstb.2009.0045

Kelan, E., 2010. Moving Bodies and Minds - The Quest for Embodiment in Teaching and Learning. High. Educ. Res. Netw. J. 3, 39-46.

Kontra, C., Goldin-Meadow, S., Beilock, S.L., 2012. Embodied Learning Across the Life Span. Top. Cogn. Sci. 4, 731-739. doi:10.1111/j.1756-8765.2012.01221.x

Kress, G., 2010. Multimodality. A social semiotic approach to contemporary communication. Routledge, London, UK.

Lakoff, G., Johnson, M., 1999. Primary Metaphor and Subjective Experience. Philos. Flesh Embodied Mind Its Chall. to West. Thought. doi:10.1590/S0102-44502001000100008

Landry, P., Pares, N., Minsky, J., Pares, R., 2012. Participatory design for exertion interfaces for children, in: Proceedings of the 11th International Conference on Interaction Design and Children - IDC '12. ACM Press, New York, NY, USA, pp. 256-259.

doi:10.1145/2307096.2307139

Lerdahl, E., Pedersen, J., 2002. Space modelling and scenario play: Mastering the complexity in the design of product networks., in: Proceedings of NordDesign 2002. 
NTNU, Trondheim, Norway.

Levinson, P., 1993. Marshall McLuhan: The medium and the messenger. J. Soc. Evol. Syst. doi:10.1016/1061-7361(93)90012-G

Lim, Y.-K., Pangam, A., Periyasami, S., Aneja, S., 2006. Comparative analysis of high- and low-fidelity prototypes for more valid usability evaluations of mobile devices, in:

Proceedings of the 4th Nordic Conference on Human-Computer Interaction Changing Roles - NordiCHI '06. ACM, New York, NY, USA, pp. 291-300.

doi:10.1145/1182475.1182506

Lim, Y.-K., Stolterman, E., Tenenberg, J., 2008. The Anatomy of Prototypes: Prototypes as Filters, Prototypes as Manifestations of Design Ideas. ACM Trans. Comput. Interact. 15, 1-27. doi:10.1145/1375761.1375762

Loke, L., Robertson, T., 2010. Studies of Dancers: Moving from Experience to Interaction Design. Int. J. Des. 4, 39-54.

Loke, L., Robertson, T., Sydney, T., 2013. Moving and Making Strange: An Embodied Approach to Movement-Based Interaction Design. ACM Trans. Comput. Interact. 20, Article No. 7.

Lyons, L., Slattery, B., Jimenez, P., Lopez, B., Moher, T., 2012. Don't forget about the sweat: Effortful embodied interaction in support of learning, in: Proceedings of the Sixth International Conference on Tangible, Embedded and Embodied Interaction (TEI '12). ACM, New York, NY, USA, pp. 77-84. doi:10.1145/2148131.2148149

Makhaeva, J., Frauenberger, C., Spiel, K., 2016. Creating creative spaces for co-designing with autistic children - The concept of a Handlungsspielraum, in: Proceedings of the 14th Participatory Design Conference (PDC '16) - Full-Papers. ACM, New York, NY, USA, pp. 51-60. doi:10.1145/2940299.2940306

Malinverni, L., Ackermann, E., Pares, N., 2016a. Experience as an Object to Think with: from Sensing-in-action to Making-Sense of action in Full-Body Interaction Learning Environments. Proc. Int. Conf. Tangible, Embed. Embodied Interact. 332-339. doi:10.1145/2839462.2839477

Malinverni, L., Lopez Silva, B., Pares, N., 2012. Impact of Embodied Interaction on Learning Processes: Design and Analysis of an Educational Application Based on Physical Activity, in: Schelhowe, $\mathrm{H}$. (Ed.), Proceedings of the 11th International Conference on Interaction Design and Children. ACM, New York, NY, USA, pp. 60-69. doi:10.1145/2307096.2307104

Malinverni, L., Mora-Guiard, J., Pares, N., 2016b. Towards Methods for Evaluating and Communicating Participatory Design: a Multimodal Approach. Int. J. Hum. Comput. Stud. 94, 53-63. doi:10.1016/j.ijhcs.2016.03.004

Malinverni, L., Pares, N., 2017. Learning from Failures in Designing and Evaluating Full-Body Interaction Learning Environments, in: Proceedings of the $2017 \mathrm{CHI}$ Conference Extended Abstracts on Human Factors in Computing Systems - CHI EA '17. ACM, New York, NY, USA, pp. 1065-1074. doi:10.1145/3027063.3053352

Malinverni, L., Pares, N., 2014a. Learning of Abstract Concepts through Full-Body Interaction: A Systematic Review. Educ. Technol. Soc. 17, 100-116.

Malinverni, L., Pares, N., 2014b. Learning of Abstract Concepts through Embodied Interaction: a 10 years systematic review of Full Body Interaction Learning Environments. J. Educ. Technol. Soc. 17, 100-116. 
Malinverni, L., Schaper, M.-M., Pares, N., 2018. Multimodal methodological approach for participatory design of Full-Body Interaction Learning Environments. Qual. Res. doi:10.1177/1468794118773299

Malinverni, L., Schaper, M., Pares, N., 2016c. An Evaluation-Driven Design approach to develop Learning Environments based on Full-Body Interaction. Educ. Technol. Res. Dev. 1-24. doi:10.1007/s11423-016-9468-z

Markopoulos, P., Read, J.C., MacFarlane, S., Höysniemi, J., 2008. The Wizard of Oz method, in: Evaluating Children's Interactive Products: Principles and Practices for Interaction Designers. Elsevier, pp. 218-233. doi:10.1016/B978-0-12-374111-0.00012-8

Márquez Segura, E., Turmo Vidal, L., Rostami, A., Waern, A., 2016. Embodied Sketching, in: Proceedings of the $2016 \mathrm{CHI}$ Conference on Human Factors in Computing Systems. ACM, New York, NY, USA, pp. 6014-6027. doi:10.1145/2858036.2858486

Mathiassen, L., 1998. Reflective systems development. Scand. J. Inf. Syst. 10, 67-118.

McLuhan, M., 1964. Understanding Media: The Extensions of Man. Gingko Press, Berkeley, CA, USA. doi: $10.2307 / 2711172$

Merleau-Ponty, M., 1962. Phenomenology of Perception. Routledge \& Kegan Paul, London, UK.

Mora-Guiard, J., Pares, N., 2014. "Child as the measure of all things": The Body as a Referent in Designing a Museum Exhibit to Understand the Nanoscale, in: Proceedings of the 2014 Conference on Interaction Design and Children - IDC '14. ACM, New York, NY, USA, pp. 27-36. doi:10.1145/2593968.2593985

Moser, C., 2012. Child-centered game development (CCGD): developing games with children at school. Pers. Ubiquitous Comput. 17, 1647-1661. doi:10.1007/s00779-0120528-z

Muller, M.J., Druin, A., 2010. Participatory Design: The third space in $\mathrm{HCl}$, in: Jacko, J., Sears, A. (Eds.), The Human-Computer Interaction Handbook. Mahway, Erlbaum, pp. 1050-1075. doi:10.1145/153571.255960

Nicol, E., Hornecker, E., 2012. Using Children's Drawings to Elicit Feedback on Interactive Museum Prototypes, in: Proceedings of the 11th International Conference on Interaction Design and Children (IDC'12). ACM, New York, NY, USA, pp. 276-279. doi:10.1145/2307096.2307144

Niedenthal, P. M.; Barsalou, L. W.; Winkielman, P.; Krauth-Gruber, S.; Ric, F., 2005. Embodiment in Attitudes, Social Perception, and Emotion. Personal. Soc. Psychol. Rev. 9, 184-211. doi:10.1207/s15327957pspr0903_1

Papert, S., 1980. Mindstorms: Children, computers and powerful ideas. Basic Books, Inc., New York, NY, USA. doi:10.1016/0732-118X(83)90034-X

Pedersen, J., Buur, J., 2000. Games and Movies: Towards Innovative Co-design with Users, in: Collaborative Design. Springer, London, UK, pp. 93-100. doi:10.1007/978-1-44710779-8_9

Piaget, J., 1955. The Child's Construction of Reality. Basic Books, Inc., New York, NY, USA.

Pietroni, E., Ray, C., Rufa, C., Pletinckx, D., Van Kampen, I., 2012. Natural interaction in VR environments for Cultural Heritage and its impact inside museums: The Etruscanning project, in: Proceedings of the 2012 18th International Conference on Virtual Systems and Multimedia, VSMM 2012: Virtual Systems in the Information Society. IEEE, Milan, 
Italy, pp. 339-346. doi:10.1109/VSMM.2012.6365943

Price, S., Jewitt, C., 2013. Interview Approaches to Researching Embodiment, in:

Proceedings of the SIGCHI Conference on Human Factors in Computing Systems $(\mathrm{CHI}$ '13). ACM, New York, NY, USA, pp. 2907-2910.

Price, S., Sakr, M., Jewitt, C., 2015. Exploring Whole-Body Interaction and Design for Museums. Interacting with Computers. Interact. Comput. 28, 569-583.

doi:10.1093/iwc/iwv032

Read, J., Macfarlane, S., Casey, C., 2002. Endurability, Engagement and Expectations: Measuring Children's Fun. Interact. Des. Child. 2, 1-23. doi:10.1.1.100.9319

Read, J.C., Gregory, P., MacFarlane, S.J., McManus, B., Gray, P., Patel, R., 2002. An investigation of participatory design with children-informant, balanced and facilitated design. Interact. Des. Child. 53-64. doi:10.1.1.109.1324

Resnick, M., 2002. Rethinking Learning in the Digital Age. Computer (Long. Beach. Calif). 46, 32-37. doi:10.1353/cj.2007.0001

Revelle, G., 2013. Applying developmental theory and research to the creation of educational games. New Dir. Child Adolesc. Dev. 2013, 31-40. doi:10.1002/cad.20029

Ringel Morris, M., Danielescu, A., Drucker, S., Fisher, D., Lee, B., Schraefel, M.., Wobbrock, J., 2014. Reducing legacy bias in gesture elicitation studies. Interactions 3, 40-45.

Rogoff, B., 1998. Apprenticeship in thinking: Cognitive development in social context. Oxford University Press, Oxford.

Sakr, M., Jewitt, C., Price, S., 2016. Mobile Experiences of Historical Place: A Multimodal Analysis of Emotional Engagement. J. Learn. Sci. 25, 51-92. doi:10.1080/10508406.2015.1115761

Scaife, M., Rogers, Y., 1998. Kids as informants: telling us what we didn't know or confirming what we knew already?, in: The Design of Children's Technology. Morgan Kaufmann Publishers Inc., San Francisco, CA, USA, pp. 27-50.

Scaife, M., Rogers, Y., Aldrich, F., Davies, M., 1997. Designing for or designing with? Informant design for interactive learning environments. Proc. SIGCHI Conf. Hum. factors Comput. Syst. - CHI '97 343-350. doi:10.1145/258549.258789

Schaper, M.-M., Malinverni, L., Pares, N., 2015. Sketching through the body: Childgenerated gestures in Full-Body Interaction Design, in: In Proceedings of the 14th International Conference on Interaction Design and Children (IDC'15). ACM, New York, NY, USA, pp. 255-258. doi:10.1145/2771839.2771890

Schaper, M.-M., Malinverni, L., Pares, N., 2014. Participatory Design Methods to Define Educational Goals for Full-Body Interaction, in: In Proceedings of the 11th Conference on Advances in Computer Entertainment Technology (ACE'14). ACM, New York, NY, USA, p. Article no. 50. doi:10.1145/2663806.2663867

Schaper, M.-M., Pares, N., 2016. Making Sense of Body and Space through Full-Body Interaction Design: A Case Study, in: In Proceedings of the 15th International Conference on Interaction Design and Children (IDC'16). ACM, New York, NY, USA. doi:10.1145/2930674.2935992

Schaper, M.-M., Santos, M., Malinverni, L., Zerbini Berro, J., Pares, N., 2018a. Learning about the Past through Situatedness, Embodied Exploration and Digital Augmentation of Cultural Heritage sites. Int. J. Hum. Comput. Stud. 114, 36-50. 
doi:10.1016/j.ijhcs.2018.01.003

Schaper, M.-M., Santos, M., Pares, N., 2018b. Orchestrating experts' assumptions and children's values in the design of Virtual Heritage experiences. Int. J. Child-Computer Interact. 17, 5-15. doi:10.1016/j.ijcci.2018.02.001

Schuler, D., Namioka, A., 1993. Participatory Design: Principles and Practices. L. Erlbaum Assoc. Inc, Hillsdale, NJ, USA. doi:10.1016/j.anclin.2007.12.004

Simonsen, J., Robertson, T., 2013. Routledge International Handbook of Participatory Design, International handbook of participatory design.

Simsarian, K.T., 2003. Take it to the Next Stage: The Roles of Role Playing in the Design Process, in: $\mathrm{CHI}$ '03 Extended Abstracts on Human Factors in Computing Systems. ACM, New York, NY, USA, pp. 1012-1013. doi:10.1145/765891.766123

Skovbjerg, H.M., Bekker, T., Barendregt, W., 2016. Being Explicit about Underlying Values, Assumptions and Views when Designing for Children in the IDC Community, in: Proceedings of the 15th International Conference on Interaction Design and Children (IDC'16). ACM, New York, NY, USA, pp. 713-719.

Soler-Adillon, J., 2009. Interactive Slide: An Interactive Playground to Promote Physical Activity and Socialization of Children, in: CHI'09 Extended Abstracts on Human Factors in Computing Systems. pp. 2407-2416. doi:http://doi.acm.org/10.1145/1520340.1520343

Soute, I., Lagerström, S., Markopoulos, P., 2013. Rapid prototyping of outdoor games for children in an iterative design process, in: Proceedings of the 12th International Conference on Interaction Design and Children - IDC '13. ACM, New York, NY, USA, pp. 74-83. doi:10.1145/2485760.2485779

Spiel, K., Frauenberger, C., Fitzpatrick, G., 2016. Experiences of autistic children with technologies. Int. J. Child-Computer Interact. doi:10.1016/j.ijcci.2016.10.007

Spiel, K., Malinverni, L., Good, J., Frauenberger, C., 2017. Participatory Evaluation with Autistic Children, in: Proceedings of the $2017 \mathrm{CHI}$ Conference on Human Factors in Computing Systems. pp. 5755-5766. doi:10.1145/3025453.3025851

Svanæs, D., 2013. Interaction Design for and with the Lived Body: Some Implications of Merleau-Ponty's Phenomenology. ACM Trans. Comput. Interact. 20, 1-30. doi:10.1145/2442106.2442114

van Dijk, T.A., 1993. Principles of Critical Discourse Analysis. Discourse Soc. 4, 249-283. doi:10.1177/0957926593004002006

Van Leeuwen, T., 2004. Introducing Social Semiotics. Psychology Press, London, UK.

Van Mechelen, M., Derboven, J., Laenen, A., Willems, B., Geerts, D., Vanden Abeele, V., 2016. The GLID method: Moving from design features to underlying values in co-design. Int. J. Hum. Comput. Stud. 97, 116-128. doi:10.1016/j.ijhcs.2016.09.005

Varela, F.J., 1996. Neurophenomenology A Methodological Remedy for the Hard Problem. J. Conscious. Stud. 3, 330-349.

Verhaegh, J., Soute, I., Kessels, A., Markopoulos, P., 2006. On the design of Camelot, an outdoor game for children, in: Proceeding of the 2006 Conference on Interaction Design and Children - IDC '06. ACM, New York, NY, USA, pp. 9-16.

doi:10.1145/1139073.1139082 
Vygotsky, L.S., 1980. Mind in society: The development of higher psychological processes. Harvard University Press., Cambridge, MA, USA. doi:10.1007/978-3-540-92784-6

Walsh, G., Foss, E., Yip, J., Druin, A., 2013. FACIT PD: a framework for analysis and creation of intergenerational techniques for participatory design, in: Proceedings of the SIGCHI Conference on Human Factors in Computing Systems (CHI '13). ACM, New York, NY, USA, pp. 2893-2902. doi:10.1145/2470654.2481400

Wilde, D., Vallgårda, A., Tomico, O., 2017. Embodied Design Ideation Methods, in: Proceedings of the $2017 \mathrm{CHI}$ Conference on Human Factors in Computing Systems CHI '17. ACM, New York, NY, USA, pp. 5158-5170. doi:10.1145/3025453.3025873

Wilson, M., 2002. Six views of embodied cognition. Psychon. Bull. Rev. 9, 625-636. doi:10.3758/BF03196322

Wobbrock, J.O., Morris, M.R., Wilson, A.D., 2009. User-defined gestures for surface computing, in: Proceedings of the SIGCHI Conference on Human Factors in Computing Systems (CHI '09). ACM, New York, NY, USA, pp. 1083-1092. doi:10.1145/1518701.1518866

Yarosh, S., Radu, I., Nw, S., Hunter, S., Rosenbaum, E., 2011. Examining Values: An Analysis of Nine Years of IDC Research, in: Proceedings of the 10th International Conference on Interaction Design and Children (IDC '11). ACM, New York, NY, USA, pp. 136-144.

Yip, J.C., Sobel, K., Pitt, C., Lee, K.J., Chen, S., Nasu, K., Pina, L.R., 2017. Examining AdultChild Interactions in Intergenerational Participatory Design, in: Proceedings of the 2017 $\mathrm{CHI}$ Conference on Human Factors in Computing Systems (CHI '17). ACM, New York, NY, USA, pp. 5742-5754. doi:10.1145/3025453.3025787

Zaman, B., 2007. Introducing contextual laddering to evaluate the likeability of games with children. Cogn. Technol. Work 10, 107-117. doi:10.1007/s10111-007-0067-y

Zuckerman, O., Resnick, M., 2005. Extending Tangible Interfaces for Education : Digital Montessori-inspired Manipulatives, in: Proceedings of the SIGCHI Conference on Human Factors in Computing Systems (CHI '05). ACM, New York, NY, USA, pp. 859868. doi:doi.org/10.1145/1054972.1055093 